\title{
Child temperament as an influence on maternal emotion socialization in preschool-aged children
}

Stephanie L. Clarke

West Virginia University

Follow this and additional works at: https://researchrepository.wvu.edu/etd

\section{Recommended Citation}

Clarke, Stephanie L., "Child temperament as an influence on maternal emotion socialization in preschoolaged children" (2012). Graduate Theses, Dissertations, and Problem Reports. 4842.

https://researchrepository.wvu.edu/etd/4842

This Thesis is protected by copyright and/or related rights. It has been brought to you by the The Research Repository @ WVU with permission from the rights-holder(s). You are free to use this Thesis in any way that is permitted by the copyright and related rights legislation that applies to your use. For other uses you must obtain permission from the rights-holder(s) directly, unless additional rights are indicated by a Creative Commons license in the record and/ or on the work itself. This Thesis has been accepted for inclusion in WVU Graduate Theses, Dissertations, and Problem Reports collection by an authorized administrator of The Research Repository @ WVU. For more information, please contact researchrepository@mail.wvu.edu. 
CHILD TEMPERAMENT AS AN INFLUENCE ON MATERNAL EMOTION SOCIALIZATION IN PRESCHOOL-AGED CHILDREN

Stephanie L. Clarke

Thesis submitted to the College of Human Resources and Education at West Virginia University

in partial fulfillment of the requirements for the degree of

Master of Arts

In Educational Psychology

With an emphasis in Child Development and Family Studies

Amy Root, Ph.D., Committee Chairperson

Suzanne Hartman, Ph.D., Member

Amy Gentzler, Ph.D., Member

Department of Technology, Learning, and Culture

Morgantown, West Virginia

2012

Keywords: child temperament; emotion socialization; preschool-aged children; child effects; maternal

Copyright 2012 Stephanie L. Clarke 


\begin{abstract}
Child Temperament as an Influence on Maternal Emotion Socialization in Preschool-Aged Children
\end{abstract}

\title{
Stephanie L. Clarke
}

The primary purpose of this study was to examine the relation between child temperament and maternal emotion socialization practices (e.g., supportive/non-supportive). Data were gathered from mothers of 3- and 4-year-olds; 51 mothers participated anonymously via Facebook, and 33 were drawn from a larger study on emotion socialization. Mothers completed a series of questionnaires, including a demographics questionnaire; the Child Behavior Questionnaire (CBQ; Putnam \& Rothbart, 2000) to assess maternal perception of child temperament, and the Coping with Children's Negative Emotions Scale (CCNES; Fabes, Poulin, Eisenberg, \& Madden-Derdich, 2002) to examine maternal responsiveness to children's emotions. Pearson $r$ correlation tests were conducted and yielded no significant findings. However, post-hoc analyses revealed when the data were examined separately for boys and girls; mothers' ratings of soothability was significantly and positively related to (a) ratings of CCNES supportive - anger and (b) ratings of CCNES supportive - fear for boys, but not for girls. In addition, mothers' rating of anger was significantly and positively related to CCNES non-supportive - fear for girls but not for boys. The tests examining 3- and 4-year-olds separately revealed one significant finding: CBQ soothability was significantly and positively related to CCNES supportive - fear for 3-year-olds, but the same significant result did not hold true for 4-year-olds. Thus, it is reasonable to conclude that child age and gender serve as influential factors of maternal emotion socialization practices (e.g., supportive/non-supportive). 


\section{Acknowledgements}

First, I would like to thank my family for their unconditional love and support throughout my college career. To my husband, T.J., you know this document almost as well as I do; thank you for understanding those many sleepless nights and early mornings. Most of all, thank you for your support and willingness to always listen; we can now display this on our mantle. Mom, Dad, and Rachel, your never-ending encouragement and belief in me gave me the confidence to keep going even when I didn't think I could. Thank you for encouraging me to pursue my dream and continue my education. I am forever grateful for your love, support and confidence in me.

Next, I would like to thank the members of my committee: Drs. Amy Root, Suzanne Hartman and Amy Gentzler. Thank you for both your positive and negative feedback as you helped to improve and strengthen my research study. To the best graduate advisor I could have ever had, Dr. Amy Root, having you as a mentor over the past few years has meant the world to me. Your knowledge and enthusiasm of child development is what brought me to this program, your immeasurable support and encouragement is what got me through it. I truly believe I wouldn't be here today if it wasn't for you. Thank you for challenging me. Thank you for helping me become a better student, a better writer, and for helping make this document and attainment of degree possible. Someday, I can only hope to be half the professor and advisor that you have been.

Of course, I must thank the faculty and staff of the Child Development and Family Studies program. A special thanks to Drs. Kristin Moilanen, Carol Markstrom, Bobbie Warash, Jessica Troilo, Reagan Curtis, Mrs. Nancy Wolfe-Dilgard, and Mrs. Judy Martin. I have truly valued each and every one of your classes; thank you for allowing me to become a better student.

A special thanks to the children and mothers of my research study, without you, this study would not have happened. I am very grateful for your time and participation. 
Last but not least, thank you to the graduate students of the CDFS program, both past and present, I have and will always value our friendship. Thank you for your support and encouragement over the years; I have learned so much from each and every one of you, thank you for your friendship. 


\section{TABLE OF CONTENTS}

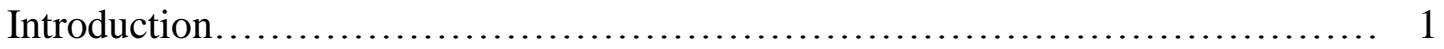

Overview........................................................................... 1

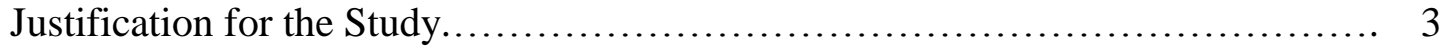

Statement of the Problem...................................................... 3

Chapter 1: Review of Literature........................................... 4

Temperament \& Parenting ............................................... 4

Child Effects............................................................ 5

Temperament and Emotion Socialization............................... 11

Influence of Temperament on Emotion Socialization....................... 13

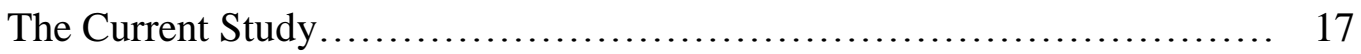

Research Question and Hypotheses.................................... 17

Chapter 2: Method........................................................... 19

Participants......................................................... 19

Procedure.............................................................. 20

Data Collection..................................................... 20

Measures............................................................. 21

Demographics................................................... 21

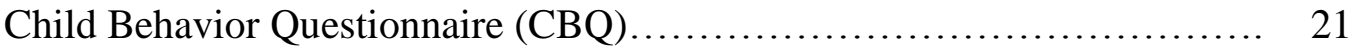

Coping with Children's Negative Emotions Scale (CCNES)............... 22

Chapter 3: Results...................................................... 24

Chapter 4: Discussion..................................................... 25

Limitations........................................................... 28 
Future Directions ............................................ 29

Conclusion.................................................. 31

References................................................. 39

Appendices......................................................... 42

Appendix A: Facebook Ad....................................... 44

Appendix B: Cover Page........................................ 45

Appendix C: Demographic Information $\ldots \ldots \ldots \ldots \ldots \ldots \ldots \ldots \ldots \ldots \ldots \ldots, 47$

Appendix D: Child Behavior Questionnaire........................ 53

Appendix E: Coping with Children's Negative Emotions Scale............ 64

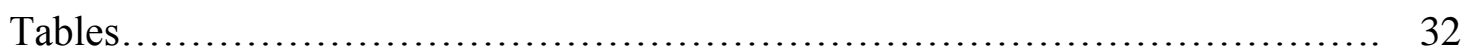

Table 1: Means and Standard Deviations of Predictor and Outcome 32 Variables.

Table 2: Correlations Between Predictor and Outcome Variables - Full 34 Sample.

Table 3: Correlations Between Predictor and Outcome Variables Boys Girls

Table 5: Correlations Between Predictor and Outcome Variables - 3-YearOlds.

Table 6: Correlations Between Predictor and Outcome Variables - 4-Year38 Olds. 


\section{Introduction}

\section{Overview}

By definition, temperament is biologically based (Allport, 1961; Rothbart \& Bates, 1998; Rothbart \& Derryberry, 1981); however it is also strongly influenced by the environment (Allport, 1961; Rothbart \& Bates, 1998; Rothbart \& Derryberry, 1981). Indeed, it is thought that individuals are born with certain temperamental characteristics (e.g., difficult/irritable, easy/soothable) and research suggests the caregiving environment plays a role in shaping these traits (Denham, Bassett, \& Wyatt, 2007; Eisenberg, Cumberland, \& Spinrad, 1998). From a goodness of fit standpoint (Thomas \& Chess, 1977), temperamental traits are malleable and may adjust depending on parenting; for example, it has been reported that infants who are highly reactive become less reactive overtime when their mothers respond sensitively and consistently to their needs (e.g., Crockenberg \& Acredolo, 1983).

While it is well-documented that parents affect children's temperament (Bates \& Pettit, 2007), there is also a body of work documenting temperament's impact on the caregiving environment (Crockenberg \& Acredolo, 1983; Crockenberg \& Leerkes, 2003; Crockenberg \& McCluskey, 1986; van den Akker, Deković, Prinzie, \& Asscher, 2010). It has been suggested that children with difficult temperamental profiles are more likely to have parents that engage in non-supportive or unresponsive parenting (Crockenberg \& Acredolo, 1983; Crockenberg \& Leerkes, 2003; Crockenberg \& McCluskey, 1986; van den Akker et al., 2010). This suggests a vicious cycle, as children's difficult temperament negatively affects his/her caregiving (Fabes, Eisenberg, Karbon, Bernzweig, Speer, \& Carlo, 1994; Fabes, Leonard, Kupanoff, \& Martin, 2001; Eisenberg, Fabes, \& Murphy, 1996), and non-supportive parenting negatively impacts difficult temperament (Fabes et al., 1994; Eisenberg et al., 1996; Fabes et al., 2001). 
While there is extensive literature on the bi-directional relation between temperament and parenting (Bates \& Pettit, 2007), very few studies have examined the relation between temperament and more specific aspects of parenting, such as emotion socialization. Emotion socialization is the process by which children learn about emotions. Parents play a vital role in the way emotions are socialized, including discussion of emotion and reactions to children's emotions. Put simply, parents can influence children's emotional development positively and negatively, depending on how they respond to their children's emotions. Specifically, parents who are sensitive to their children's emotional displays will have a positive impact on their children's overall emotional competence (or adaptive emotion expression, understanding, and regulation; Denham et al., 2007; Eisenberg et al., 1998) during childhood. In turn, emotional competence has been associated with adaptive social functioning, including prosocial behavior (e.g., empathy, sympathy, emotion-regulation skills; Denham et al., 2007; Eisenberg et al., 1998) and social competence in middle childhood and adolescence (Denham et al., 2007; Eisenberg et al., 1998). In contrast, parents who are unresponsive or insensitive to their children's emotions have children who suffer socially and emotionally. For example, parents' who minimize (i.e., devalue) their children's emotional displays dissipate their children's emotional understanding (Denham et al., 2007).

Thus, it is clear that obtaining a better understanding of potential predictors of emotion socialization practices will provide a better understanding of why some parents engage in supportive emotion socialization practices while others respond to their children's emotions in unsupportive ways. 


\section{Justification for the Study}

After an extensive review of the literature, it appears that there is a paucity of our understanding of how children's temperament influences emotion socialization. Specifically, how temperament impacts how parents socialize emotions. In particular, it seems critical to understand the way in which a child's temperament impacts the emotion-specific caregiving environment given the links between emotion socialization and emotional competence, and emotional competence and later socio-emotional adjustment (Denham et al., 2007; Eisenberg et al., 1998). Thus, taking what we know (from the literature) into account, there is strong evidence provided for the importance of examining temperament as a predictor of both general and specific emotions, an area that has been rarely studied (i.e., most studies examine the socialization of an aggregate of negative emotions).

\section{Statement of the Problem}

The primary purpose of this study was to examine the relation between child temperament and emotion-related parenting practices (e.g., supportive/non-supportive). Many researchers would agree of the importance in examining how children's temperament influences emotion socialization, however, this area of research is very limited. Moreover, in the few studies that have examined the links between temperament and emotion socialization, none have examined the relation between temperament and parents' reactions to specific emotions (e.g., anger and fear vs. negative emotions). Therefore, a secondary aim of the proposed study was to examine the relation between child temperament and specific emotion socialization beliefs, namely to anger and fear. 


\section{CHAPTER I}

\section{Review of Literature}

For the past few decades, the study of the emotion socialization has been a central area of study in the field of child development. Researchers have sought to investigate many aspects of the socialization process (e.g., parent and child characteristics) and how socialization affects later development. Although this is a growing topic of study, there is considerable evidence indicating that parents' emotion socialization practices influence children's social and emotional competence (Denham et al., 2007; Eisenberg et al., 1998; Kennedy Root \& Denham, 2010). However, we are only beginning to understand what influences parents' socialization practices and there is little work devoted to understanding the influence of children's dispositional characteristics on parents' emotion socialization practices. Thus, this study examined the way in which child temperament influences emotion-related parenting practices. This area of study seems critical because by understanding how children impact their caregiving environment we can pinpoint predictors of adaptive and maladaptive socialization strategies. This will likely provide a better understanding of the development of children's social and emotional outcomes (e.g., emotional understanding, expressivity, regulation; prosocial behavior, peer relationships).

In the literature review below, I will begin by providing a brief overview of temperament.

Next I will review the empirical literature that indicates how temperament impacts the caregiving environment. I will then provide an overview of emotion socialization and review the few studies that have examined the influence of temperament on the process of emotion socialization.

\section{Temperament \& Parenting}

According to many developmental researchers, temperament is biologically based (Allport, 1961; Rothbart \& Bates, 1998; Rothbart \& Derryberry, 1981), however a more in depth 
understanding of how the environment influences temperament continues to advance in research today. Rothbart and Bates (1998) and Rothbart and Derryberry (1981) define temperament as a biological basis to explain differences among individuals in both reactivity (e.g., emotional responsiveness to environmental changes) and self-regulation (e.g., effortful control). Unlike personality, temperament is not continuously expressed (e.g. through thought or feeling), but rather, elicited under specific conditions. However, studies have demonstrated that temperamental traits demonstrate short term stability and are predictive of later behavior (see Rothbart \& Bates, 2006 for recent review).

Child Effects. Research has suggested that temperament impacts not only the individual but almost every context in which the individual is in, such as the caregiving environment (e.g., Bell \& Chapman, 1986), school (e.g., Crockenberg \& Leerkes, 2003), and peer relationships (e.g., Crockenberg \& Leerkes, 2003). For example, children with a difficult temperamental profile tend to have a hard time adjusting to school activities (Crockenberg \& Leerkes, 2003); they tend to engage in aggressive interactions, as well as have poor relationships with siblings and/or peers (Crockenberg \& Leerkes, 2003). In addition, there is evidence that shows children of difficult temperament are likely to elicit unresponsive or non-supportive parenting (Fabes et al., 1994; Fabes et al., 2001; Eisenberg et al., 1996). In contrast, individuals who have an easy temperament are likely to elicit warm, responsive caregiving (Fabes et al., 1994; Fabes et al., 2001; Eisenberg et al., 1996), have positive peer relationships as well as have an easier time adjusting in certain situations (Fabes et al., 1994; Fabes et al., 2001; Eisenberg et al., 1996). Thus, it clear that children exert an influence on their interactions and relationships with others. Bell and Chapman (1986) introduced a control system model as a theoretical framework to explain: how individual differences in infants and children elicit different parenting styles, and 
how parents and children regulate each other's behavior. Specifically, this model proposes that children's traits influence their caregiving environment and this model has indicated that negative parenting is especially susceptible to children's dispositional traits such as negative reactivity (Lytton, 1991). According to Bell and Chapman (1986), the ultimate goal of this model is to achieve a reciprocated balance of socialization between parents and children. For example, parents and children achieve a reciprocated balance of socialization by means of regulating (i.e. reducing or increasing) the behavior of one another. It is through the balance of socialization that the ground work for an effective caregiving environment is laid. Thus, it seems critically important to understand how children impact their caregiving environment.

There is empirical support for this model in samples of infants and preschoolers. For instance, the work of Susan Crockenberg and colleagues has illuminated the links between child temperament and parenting. For example, Crockenberg and Acredolo (1983) examined maternal ratings and perceptions of infant temperament and the influential impact it has on maternal caregiving. Fifty-six mothers and infants were investigated. The Neonatal Behavioral Assessment Scale (NBAS) was administered at one- and three-months to assess infants' alertness and irritability. In addition, mothers completed the Infant Behavioral Questionnaire (IBQ) at three-months as an assessment of infant temperament. The following temperament dimensions were measured using the Infant Behavior Questionnaire: activity level (e.g., gross motor), joy/happiness (e.g., smiling/laughter), distress (e.g., fussing/crying), soothability (e.g., reduction of fussing/crying), and length of orientation (e.g., duration of interaction). Mothers and infants were also observed in the home to assess mothers' interactions and involvement with infant, as well as infant's temperament (e.g., frequency/intensity of emotional states). Using a hierarchical regression and correlation analyses, the authors reported that irritable newborns tended to be less 
alert at one-month observations, and consequently received less involvement/contact from their mother (Crockenberg \& Acredolo, 1983); thus, suggesting that more alert/less irritable babies received more maternal attention (Crockenberg \& Acredolo, 1983). In addition, Crockenberg and Acredolo (1983) found that more difficult, irritable infants received less maternal involvement, which in turn impacts maternal ratings of infant temperament. The authors concluded that irritable infants make the caregiving environment more difficult and thus pose a challenge to caregivers, specifically mothers.

Crockenberg and colleagues have also provided longitudinal evidence of child effects. For instance, Crockenberg and McCluskey (1986) examined the change that occurs in maternal sensitivity and responsiveness over the first year of life, with a focus on how infant temperament impacts these processes. Specifically, the authors, as part of a larger study, examined the influence of infant irritability on maternal behavior over one year. They sought to understand the change in maternal responsiveness over a 9-month period depending on infant temperament. Infant irritability was assessed via a home administered Neonatal Behavioral Assessment Scale (NBAS) shortly after birth. Mothers' responsiveness was assessed at two time points: (1) at 3 months via observations in the home and (2) at 12 months via observations in the laboratory via the Strange Situation (Ainsworth \& Wittig, 1969). Crockenberg and McCluskey (1986) found that child effects, specifically difficult/irritable temperament influenced maternal responsiveness over the first year. Specifically, they found that irritable babies had mothers who were less responsive and less sensitive to them over time (Crockenberg \& McCluskey, 1986). In addition, Crockenberg and McCluskey (1986) found that difficult infant temperament was associated with maternal unresponsiveness early on, suggesting that infant irritability may elicit a vicious cycle of unresponsive caregiving as early as the third month of life. 
Evidence for child effects has also been shown in research conducted by individuals other than Crockenberg and colleagues. For instance, in a more recent study, it was also found that temperament influences parenting beyond the first year of life. In this study, van den Akker and colleagues (2010) examined three temperamental typologies over the course of one year. The authors examined how infants' temperamental profiles adjust to trajectories of positive and negative parenting throughout the preschool years. They expected infants of adaptive temperamental profiles (e.g., low negative reactivity) to be associated with trajectories of positive parenting, and in contrast, infants of less adaptive temperamental profiles (e.g., high negative reactivity) to be associated with trajectories of more negative parenting. This longitudinal study included 96 Dutch mothers and their infants at 30-, 36-, 39-, and 42-months. Infant temperament was measured using the short version of the Toddler Behavior Assessment Questionnaire (Goldsmith, 1996) to assess activity level, anger proneness, and social fearfulness. Parenting was observed in the home via free play, two Lego building tasks, and a clean-up task. Parenting was assessed through coding of observations using the Coder Impressions Inventory (CII; Webster-Stratton, 1998); the Erickson rating scales (Erickson et al., 1985), and the Parenting Dimensions Inventory (PDI; Slater and Power, 1987). From these scales, the following negative parenting dimensions were measured: harshness; hostility; and negative control. The following positive parenting dimensions were also coded: support; consistency; and responsiveness.

First, the authors analyzed the data to elucidate different temperament profiles based on the TBAQ dimensions. They reported that the data indicated there were three temperamental profiles: typical (lowest scores on social fear, anger proneness, and activity level); expressive (moderate levels of social fear and the highest levels of anger proneness and activity level); and 
fearful (highest levels of social fear; and intermediate levels of anger proneness and activity level). Second, the authors examined the association between the temperamental profiles and parenting. When examining levels of positive parenting, van den Akker et al. (2010) reported that the fearful and expressive groups had parents who were rated as less positive in their parenting, whereas the typical group had parents who were rated as more positive in their parenting. There were no associations between temperament and negative parenting for any of the profiles.

When the researchers examined change in parenting over time, they found that the trajectories for the expressive and fear groups indicated a stronger increase in positive parenting when compared to the trajectory for the typical group, which indicated a modest increase in positive parenting over time (van den Akker et al., 2010). Moreover, they found when children "moved" from one profile to another there were changes in parenting over time. Specifically, if a child transitioned from the fearful or expressive group to the typical group they had parents who were more positive over time; however, if a child moved from the typical group to one of the other profiles, an increase in positive parenting wasn't as apparent. The findings from this article suggests a bidirectional association between the development of temperamental profiles and positive and negative parenting over time; specifically as one changes, so does the other (van den Akker et al., 2010).

There is also some evidence in the child effects literature that parents may be attuned to their children's temperament and thus, adjust their parenting practices accordingly. For instance, in a short-term longitudinal study, Paulssen-Hoogeboom, Stams, Hermanns, \& Peetsma (2008) examined how negative emotionality (e.g., difficult temperament) influences maternal behavior (e.g., sensitivity/responsiveness) during the preschool years. In this study, 59 preschool-aged 
Dutch children and their mothers were included. The authors sought to examine the participants among two different groups: low levels of negative emotionality (i.e., easy temperament) and high levels of negative emotionality (i.e., difficult temperament). Children's negative emotionality was measured by creating the Negative Affectivity subscale from the Children's Behavior Questionnaire (CBQ). The subscale comprised the following dimensions: anger/frustration (e.g., negative emotionality to task interruption), discomfort (e.g., negative emotionality to sensory perception), fear (e.g., inhibition), sadness (e.g., negative emotionality/disappointment), and soothability (e.g., reduction of distress/excitement). Maternal sensitive responsiveness was measured via videotaped observations, during a 12-minute structured play task (e.g., Lego blocks). Contrary to the existing literature, Paulssen-Hoogeboom et al. (2008) reported that mothers who rated their child having a difficult temperament (i.e. high negative emotionality) were more responsive and sensitive than mothers who rated their child as having an easy temperament (e.g. low negative emotionality). The authors surmised that children high in negative emotionality had mothers who provided care accordingly; thus suggesting the needs of the difficult child were met. More specifically, they reported that mothers of difficult children provided care by permitting independence yet intervening when needed and providing instructional guidance during play, in addition to being responsive. Thus, the authors surmised that mothers of more difficult children are required to utilize a broader array of parenting practices more than mothers whose children are less difficult (i.e., easy temperament). The preceding results provide additional evidence to the child effects literature however, it appears that in addition to difficult temperament impacting parenting in a negative way, it seems from this study that children's negative emotionality may require mothers to respond in a more sensitive and responsive way. 
While the abovementioned studies provide evidence for the way in which temperament impacts the caregiving environment, there continues to be a gap in the literature concerning how child temperament influences the process of emotion socialization. There have been a few studies that have examined the influence of child temperament on emotion socialization, but these examinations are limited. Moreover, the existing literature is limited in that no studies to date have examined how temperament may influence parents' reactions to specific emotions (i.e., anger and fear rather than an aggregate of negative emotion). It seems important to understand parents' reactions to anger and fear (rather than an aggregate of the two) because these emotions are particularly salient during the preschool years, particularly in the peer group (Denham, 1998). Moreover, these are emotions that children likely need their parents' assistance in generating strategies to regulate; and, thus, it seems important to understand what may influence parents' socialization strategies. As aforementioned, the aim of the proposed study is to examine temperament as a predictor of specific emotion socialization strategies, namely anger and fear. Therefore, I will next provide a brief overview of the process of emotion socialization and review the studies that have examined the relation between temperament and emotion socialization.

\section{Temperament and Emotion Socialization}

Emotions are biologically based, but caregiving experiences dictate how emotions are experienced and expressed (Saarni, Mumme, \& Campos, 1998). Specifically, it is suggested that emotions are influenced via the socialization process, and occurs most often via interactions among family members during the early years of life (Denham et al., 2007; Kennedy Root \& Denham, 2010). For example, parent-child interactions provide a context for parents' to socialize emotions in their children. Denham et al. (2007) proposed three ways in which 
socialization of emotion occurs in children: (a) observing the feelings and emotions of others, (b) parental responsiveness to their feelings and emotions and (c) learning about their feelings and emotions. Thus, emotions are socialized via direct and indirect ways (Eisenberg et al., 1998). Direct socialization refers to parental reactions (i.e., responsiveness) to their child's emotions as well as parent-child discussion of emotions. For example, parents directly impact their children's emotional competence by the way they react and respond to their children's emotions. Indirect socialization typically refers to the emotional "climate" in the family (e.g., what emotions are expressed and the intensity that emotions are expressed). Although the influence of indirect socialization is important to the development of emotion, for the purposes of this study, I exclusively examined the direct socialization practices elicited by parents and therefore will only review studies on direct emotion socialization herein.

Researchers have typically characterized parental responses to children's emotions as either supportive or nonsupportive. Supportive parenting includes appropriate responses to children's positive and negative emotionality in an encouraging and comforting way. For example, parents' who are attentive to their children's emotional displays. Consequently, supportive parental reactions are related to children's enhanced development of emotional understanding, emotion regulation as well emotion expressivity (Denham et al., 2007; Kennedy Root \& Denham, 2010). In contrast, nonsupportive parenting includes parents who are unresponsive and/or insensitive to emotional displays of their children. For example, parents' who minimize their children's emotional displays. Thus, nonsupportive parental reactions are related to diminishing children's emotional development, specifically their emotional understanding (Denham et al., 2007; Kennedy Root \& Denham, 2010). 
Supportive and nonsupportive emotion socialization has often been measured using the Coping with Children's Negative Emotions Scale (CCNES; Fabes, Eisenberg, \& Bernzweig, 1990). This self-report measure asks parents to rate a variety of reactions to their children's negative display(s) of emotions in 12 hypothetical situations. Specifically, they are asked to rate their reactions to their children's displays of anger, sadness, fear, embarrassment, and disappointment. These reactions are then placed into six categories: distress reactions (the degree to which parents experience distress when children express negative affect); punitive reactions (the degree to which parents respond with punitive reactions that decrease their exposure or need to deal with negative emotions of their children); expressive encouragement (the degree to which parents encourage children to express negative affect or the degree to which they validate child's negative emotional states); emotion-focused reactions (the degree to which parents respond with strategies that are designed to help the child feel better); problem-focused reactions (the degree to which parents help the child solve the problem that caused the child distress); and minimization reactions (the degree to which parents minimize the seriousness the situation or devalue the child's problem or distressful reaction) (Fabes et al., 1990). To conclude, the Coping with Children's Negative Emotions Scale (CCNES) is a reliable and valid assessment in measuring how parents' respond to their children's negative emotions.

The influence of temperament on emotion socialization. While there is a growing body of literature on the effects of emotion socialization on children's later social and emotional development, there is a relative paucity in our understanding of the way that children's characteristics may impact parents' emotion socialization beliefs and practices. There are a handful of studies that have examined the effect of child temperament on parents' emotion socialization beliefs and practices. In one of the few studies that has examined these relations, it 
was found that there appear to be relations between temperament and emotion socialization. Fabes et al. (1994) examined interactions among mothers and their children via laboratory observations related to maternal perception of child temperament (i.e., emotional reactivity). Participants in the study included 49 kindergartners and 54 second graders, and their mothers. Mothers and children were invited to a laboratory where, upon arrival, mothers were informed they would tell their child two stories; both stories were entirely depicted by pictures and contained children in distress (i.e., sorrow, anguish, pain) within a specific situation. One story, referred to as "the accident story," consisted of the child character cutting his/her head open after attempting to climb a tree and falling down. The child was then taken to the doctor's office, where he/she was comforted by his/her parents as he/she got stitches. Later, the child was illustrated telling the other children about his/her accident and what happened. The second story, referred to as "the pet story," consisted of a child character being sad because his/her pet had become sick, and eventually passed away in the story. The child character in the story, known as "Sandy," was very saddened due to the loss, while his/her parents tried to comfort him or her. Later, it was illustrated that Sandy was so upset that he/she pushed another student down at school. Thus, the teacher as depicted in the story comforted and talked to the hurt student. As a result, Sandy cried and was comforted by a friend. In the end of the story, Sandy was happy again, as she picked out a new puppy. During the storytelling task, mothers' behavior was coded for maternal warmth (e.g., the amount of eye contact and positive affect directed toward the child during the story) and attentional directiveness (e.g., telling her child to attend to the story or to an event that recently happened to the child); in addition, mothers' facial expressions (e.g., display of happiness, sadness, distressed, disgusted, and concerned) were coded on scale from no display of emotion (i.e., being a 1) to strong display of emotion (i.e., being a 5). The authors then 
created a composite score of negative emotion from the sadness and distress codes (disgust and concerned attention occurred infrequently and were excluded from the analyses). The authors found mothers' negative facial expressions while telling the stories was positively associated with maternal perceptions of child temperament (i.e., emotional reactivity; Fabes et al., 1994). In other words, how mothers' perceived their child's emotional reactivity was positively associated with the way in which they expressed either positive or negative facial expressions while telling the stories. In addition, the authors suggested maternal responsiveness during the storytelling interaction was largely influenced by maternal perception of how emotionally reactive their child is likely to become when others' show sign of distress (Fabes et al., 1994). In sum, the presented findings suggest children's temperament is related to the ways in which mothers' react to children's emotions.

Eisenberg et al. (1996) also examined the association between parents' reactions to negative emotionality and children's temperament, as part of a larger study on the development of social competence in school-age children. Participants included 148 children recruited from three elementary schools, ranging from the third, fourth, and fifth grade and their parents. Parents' emotion socialization beliefs were assessed via the Coping with Children's Negative Emotions Scale (CCNES), which is a questionnaire that asks parents to rate their responses to children's emotions depicted in 12 situations. The responses are categorized as supportive (encourage expression of emotion, emotion-focused socialization reactions, problem-focused socialization reactions) or unsupportive (parental distress reactions, punitive responses, and minimizing responses). In addition, negative emotionality (temperament) was measured via Derryberry and Rothbart's (1988) temperament measure to assess aspects of negative emotionality. Eisenberg et al. (1996) found nonsupportive maternal reactions positively 
associated with parental reports of child's negative emotionality. In other words, the authors found that mothers who rated their child as high in negative emotionality were more likely to report non-supportive reactions to their children's emotions. However, the same did not hold true for supportive maternal reactions; in fact there was no association between children's negative emotionality and maternal supportive reactions to children's emotions.

In another study, Fabes et al. (2001) examined the relation between parents' reactions to children's negative emotions and social competence longitudinally. Fifty-seven preschool-aged children and their parents' were recruited from various preschool and kindergarten classrooms. Daily school observations were used to measure children's negative emotionality. Parental reactions to children's negative emotions were measured via The Coping with Children's Negative Emotions Scale (CCNES). Harsh and distressed parental responses were the focal point for this measure, which included: punitive responses (e.g., the degree to which parents respond with punitive, or controlling responses that decrease their exposure or need to deal with the negative emotions of their children), minimization responses (e.g., the degree to which parents minimize the seriousness of the situation or devalue the child's problem or emotional response), and distress responses (e.g., the degree to which parents experience negative emotional arousal when children express negative affect) (Fabes et al., 2001). Results indicated that harsh parental coping (an aggregate of punitive and minimization scales) was positively associated with children's emotional reactivity (i.e., emotional arousal). In other words, children who were observed to engage in high levels of emotional reactivity and very intense levels of negative emotion had parents who endorsed harsh reactions to children's emotions (e.g., parent's lack of acknowledgement or minimization of their children's emotions) elicited. 


\section{The Current Study}

In sum, it appeared that there was a relation between temperament and emotion socialization, however our knowledge is limited. Many researchers would agree of the importance in further understanding how child temperament impacts the caregiving environment, provided the recent evidence of the link between parents' emotion socialization practices and the development of emotional competence (Denham et al., 2007; Eisenberg et al., 1998). Therefore, it seemed critical to better understand the factors that influence parents' emotion socialization practices. Indeed, one can concur further examinations were needed. Moreover, in the few studies that have examined how temperament influences emotion socialization, none have examined the relation between temperament and emotion-specific parental reactions. This area of study seems important given evidence from the emotions socialization literature has indicated that examining both global and specific emotion socialization strategies provides a powerful prediction of children's subsequent behavior (e.g., O'Neal \& Magai, 2005). Thus, the purpose of this study was to extend the existing work to include: (1) a sample of preschool-aged children and (2) examine specific negative emotions: anger and fear.

Research question and hypotheses. The current study examined the following research question: Does children's anger/frustration and falling reactivity/soothability affect maternal emotion socialization beliefs?

The following specific hypotheses were generated to address this larger research question:

Hypothesis 1: Anger/frustration - supportive anger. It was expected that there would be a negative relation between anger/frustration and supportive reactions to children's anger. 
Hypothesis 2: Anger/frustration-non-supportive anger. It was expected that there would be a positive relation between anger/frustration and non-supportive reactions to children's anger.

Hypothesis 3: Soothability - supportive anger \& fear. It was expected that there would a positive relation between soothability and supportive-anger and supportive-fear.

Hypothesis 4: Soothability - non-supportive anger \& fear. It was expected that there would be a negative relation between soothability and non-supportive anger and non-supportive fear.

Hypotheses 5 \& 6: - No specific hypotheses were offered for the analyses conducted examining the relation between anger/frustration and supportive fear and non-supportive fear due to the exploratory nature of these analyses. 


\section{CHAPTER II}

\section{Method}

\section{Participants}

Data from mothers of 84 children (50 3-year-olds and 34 4-year-olds; 36 boys and 48 girls) participated in this study from two different samples. 51 mothers of preschoolers were recruited anonymously via Facebook and completed the surveys online (hereafter referred to as the "Facebook sample"). The Facebook sample resided in states included in the U.S. Census Division 5 (South Atlantic region: Delaware, Maryland, District of Columbia, Virginia, West Virginia, North Carolina, South Carolina, Georgia, or Florida). In addition, 33 participants were drawn from a larger longitudinal study (hereafter referred to as the "Longitudinal sample"). In the longitudinal study, participants were also recruited via flyers, advertisements and letters to local preschools in Morgantown, West Virginia.

All mothers completed a battery of questionnaires, including a demographics questionnaire, a questionnaire about their child's temperament, and a questionnaire about their emotion socialization beliefs; however, the mothers from the longitudinal sample completed additional questionnaires that were not relevant to the present study. Importantly, all mothers completed the questionnaires used herein via Survey Monkey and in the same order: (1) demographics, (2) temperament inventory, and (3) emotion socialization beliefs questionnaire.

The samples were compared on demographic information (e.g., child age, child sex, maternal age, and household income) and no differences were found. The data gathered from the 51 participants were combined with existing data from 33 mothers of 3-and 4-year-old children who participated in a larger multi-method study on emotion socialization all of who completed the surveys online via the same software as the Facebook sample (i.e., Survey Monkey). The 
entire sample comprised primarily of White or Caucasian mothers (93\%) and White or Caucasian children (89\%) of non-Hispanic or Latino ethnicity (Mothers 1\% Hispanic or Latino; children 2\% Hispanic or Latino). Mothers age ranged from 18 to 47 years of age (mean age $=$ 33). The average reported income was in the $\$ 75,000$ - $\$ 100,000$ range per year and most mothers $(84 \%)$ reported earning at least a University degree.

\section{Procedure}

Facebook Sample. Participants were recruited anonymously via a social network site, Facebook. An advertisement (see Appendix A) was posted on personal Facebook pages to recruit mothers of 3-and 4-year-old children. If mothers were interested they would click on a link to bring them to the website where the questionnaires were housed (via Survey Monkey). On the first page, they encountered an explanation of the study (see Appendix B). If participants agreed, they would then proceed to the questionnaires. A total of three questionnaires were used in the study: a demographics questionnaire; a questionnaire regarding maternal perception of child temperament (e.g., $C B Q$; Putnam \& Rothbart, 2000); and a questionnaire concerning maternal responsiveness to children's emotions (e.g., CCNES; Fabes, Poulin, Eisenberg, \& Madden-Derdich, 2002). The questionnaires took approximately 20 minutes to complete. Upon completion, participants were given the option to email the researcher for a chance to enter into a drawing for one of four gift cards to Wal-Mart, valued at $\$ 25.00$.

Longitudinal Sample. The longitudinal sample comprised data from mothers of 3- and 4-year-olds who completed questionnaires online (CBQ; Putnam \& Rothbart, 2000; CCNES; Fabes et al., 2002) as part of a larger study on emotion socialization. This sample was recruited via local advertisements, distribution of recruitment flyers and letters to local preschools in Morgantown, West Virginia. Participants in the longitudinal sample had the option of 
completing a larger battery or questionnaires online or on paper; only the mothers who completed the questionnaires online were included herein. For the longitudinal sample, all participants received a $\$ 20.00$ gift card to Wal-Mart or Target.

Both samples. Completion of questionnaires followed the same procedures as noted above for the Facebook sample, and participants in both sample provided consent prior to accessing the questionnaires.

\section{Measures}

Demographics. Mothers completed a basic demographic questionnaire (Appendix C). Questions included: their children's age, race/ethnicity, mother's age, mother's race/ethnicity, father's age, father's race/ethnicity, and family income. In addition, mothers completed items regarding marital status and previous marriages.

Child Behavior Questionnaire (CBQ.) Mothers' completed the 94-item short-form of the Child Behavior Questionnaire (Putnam \& Rothbart, 2006) (Appendix D). This measure comprises factors that assess parental perceptions of their child's temperament. Of specific interest to this study are the factors assessing anger/frustration (6 items, e.g., child gets angry or mad when he/she doesn't get something he/she wants, gets angry when he/she is told can't do something he/she wants; Cronbach's $\alpha=.67$ ) and falling reactivity/soothability (6 items, e.g., easy to cheer up when upset, cheers up quickly when s/he thinks about something else; Cronbach's $\alpha=.58)$. Items were scored on a 7-point Likert-type scale (e.g. $1=$ extremely untrue of your child, 2 = quite untrue of your child, 3 = slightly untrue of your child, $4=$ neither true nor false of your child, 5 = slightly true of your child, $6=$ quite true of your child, $7=$ extremely true of your child). Scores ranged from 6 (extremely untrue of your child) to 42 (extremely true of your child) on the scale of anger/frustration. In addition, scores ranged from 6 (extremely 
untrue of your child) to 42 (extremely true of your child) on the scale of falling reactivity/soothability.

Coping with Children's Negative Emotions Scale (CCNES). Mothers' completed an adapted version of the Coping with Children's Negative Emotions Scale (Fabes et al., 2002) (Appendix E). This measure comprises six-subscales that assess parental reactions to their child's negative emotional displays. Of specific interest to this study are the factors assessing supportive parental reactions, for example, expressive encouragement (e.g., encourage my child to express his/her feelings of anger and frustration; emotion-focused responses (e.g., soothe my child and do something fun with him/her to make him/her feel better); problem-focused responses (e.g., help my child think about ways that he/she can still be with friends) and nonsupportive parental responses, for example, distress reactions (e.g., get angry at my child), punitive responses (e.g., send child to his or her room), and minimization responses (e.g., tell my child not to make a big deal). Items were scored on a 7-point Likert-type scale, from 1 (very unlikely) to 7 (very likely). Scores ranged from 7 (very unlikely) to 49 (very likely) on all of the following scales: expressive encouragement (Cronbach's $\alpha=.92$ ), emotion-focused responses (Cronbach's $\alpha=.81$ ), problem-focused responses (Cronbach's $\alpha=.80$ ), distress reactions (Cronbach's $\alpha=.41$ ), punitive responses (Cronbach's $\alpha=.60$ ), and minimization responses (Cronbach's $\alpha=.75)$.

\section{Data Reduction}

Consistent with previous studies (e.g., Fabes et al., 2002), the following factors were computed from the above-noted CCNES subscales: supportive reactions (emotion focused + problem focused + expressive encouragement) and non-supportive reactions (minimization + punitive). Furthermore, these subscales were computed separately for the anger and fear 
questions, which resulted in four variables: supportive anger (Cronbach's $\alpha=.76$ ), supportive fear (Cronbach's $\alpha=.85)$, non-supportive anger (Cronbach's $\alpha=.66)$, and non-supportive fear (Cronbach's $\alpha=.74)$. 


\section{CHAPTER IV}

Results

The means, standard deviations, and table of correlations are presented in Tables 1 and 2. First, an independent samples t-test was conducted to ascertain if the two samples (longitudinal sample and Facebook sample) were significantly different on any of the variables of interest; the series of t-tests yielded no significant differences between the two samples on the $C B Q$ subscales and the CCNES subscales.

Next, a series of Pearson $r$ correlation tests were conducted to test hypotheses $1-6$; no significant findings were yielded from these tests. As a result, post-hoc analyses were conducted to examine if significant relations would be detected if the correlations were run separately for: (a) boys and girls and (b) 3-year-olds and 4-year-olds.

When the data were examined separately for boys and girls; mothers' ratings of soothability was significantly and positively related to (a) ratings of CCNES supportive - anger and (b) ratings of CCNES supportive - fear for boys, but not for girls. In addition, mothers' rating of anger was significantly and positively related to CCNES non-supportive -fear for girls but not for boys (see Table 2).

For the tests examining 3- and 4-year-olds separately, one significant finding was revealed (see Table 2): CBQ soothability was significantly and positively related to CCNES supportive -fear for 3-year-olds, but the same significant result did not hold true for 4-year-olds (see Table 2). 


\section{CHAPTER V}

\section{Discussion}

The primary purpose of the current research study was to examine the relation between child temperament and maternal emotion socialization practices (e.g., supportive/nonsupportive). It was my goal to examine child effects (Bell \& Chapman, 1986) on maternal emotion socialization beliefs. Specifically, maternal perceptions of children's temperamental anger/frustration and soothability were examined in relation to mothers' report of reactions to children's anger and fear. When the data were examined on a whole, no significant relations were found. Thus, the hypotheses were not confirmed; however, post hoc analyses were then conducted to examine if relations between child temperament and emotion socialization could be detected when examining the data separately for: (a) boys and girls and (b) 3-year-olds and 4year-olds.

When the data were examined separately by sex, findings indicated that maternal ratings of soothability was significantly and positively related to maternal ratings of supportive - anger and supportive - fear for boys, but not for girls. Therefore, mothers' who rated their son's temperament as highly soothable reported high levels of supportive reactions to their son's displays of anger and fear, however the same was not true for their daughters. In other words, mothers who perceived their son's temperament as easy or soothable responded with more supportive reactions (i.e., responsiveness) to their son's negative emotional displays of anger and fear. This may be an example of child effects, however, given the correlational nature of the data, it is difficult to ascertain the direction of the effect. Thus, it may be that mothers view their sons as more soothable because they are supportive when they are displaying negative emotions. Perhaps mothers that have invested in their son's emotional development by responding to their 
emotions via supportive strategies view their children as more regulated. It is important to note that this is speculation, as the data were not longitudinal. Thus, this requires additional study.

This does not explain why these effects were found for boys, but not for girls. There is some evidence from the infant literature that indicates mothers may be more "invested" in their son's regulation of negative affect over their daughters due to biological differences. In other words, mothers may be more inclined to "down regulate" their sons' displays of emotions due to gender differences in emotional traits such as anger proneness (see Rothbart \& Bates, 2006 for review), with boys often displaying more anger/frustration early in life. Indeed, Malatesta and Haviland (1982) reported that mothers responded more contingently to their sons' emotions than their daughters; they explained that mothers may feel a greater need to reinforce their sons' emotions more than their daughters because of dispositional sex differences in affective displays.

Further support for this explanation can be found when examining the correlations between mothers' perceptions of their daughters' soothability and their report of supportive reactions to anger and fear (see Table 4); they were near zero.

Results also indicated that mothers' rating of children's anger was significantly and positively related to CCNES non-supportive - fear for girls, but not for boys. Therefore, mothers' who rated their daughter's temperament as high in anger/frustration reported nonsupportive maternal reactions to their daughter's negative emotional display of fear, however, the same result was not found for boys. Mothers may simply expect their daughters to control their negative emotions, especially those that have ramifications for interpersonal relationships. There are some studies that have documented that parents (both mothers and fathers) discuss emotions with their daughters in an interpersonal fashion (Fivush, Brotman, Buckner, \& Goodman, 2000), which supports this interpretation. It may also be that mothers in this sample perceive their 
daughters as less soothable because they are not as supportive to their daughters' display of negative emotions. Perhaps mothers have not invested as much time in their daughter's emotional development and therefore respond in a more non-supportive fashion, thus viewing their daughters' as less soothable.

On the other hand, if mothers perceive their daughters to have the tendency to display a lot of anger, they may not know how to handle any of their emotions, including fear; thus, they may respond in non-supportive ways to all emotions. Indeed, this finding may also reflect that mothers aren't used to their daughters negative emotional displays and this is their "global" reaction to their daughters' negative emotions. Indeed, the correlation between anger/frustration and non-supportive anger were positive, but not significant (see Table $4, r=.19$ ).

With regards to child age, when 3- and 4-year-olds were examined separately, one significant finding revealed that maternal ratings of children's soothability was significantly and positively related to CCNES supportive - fear for 3-year-olds, but not for 4-year-olds. Thus, mothers' who rated their 3-year-old's as soothable reported supportive maternal reactions to their 3-year-olds negative emotional display of fear. However, the same significant finding did not hold true for 4-year-olds. Therefore, it appears that as children get older, mothers may expect more emotion-related independence from their children. In other words, with age, it seems that mothers' may hold their children to a higher standard with regards to their display of negative emotions (e.g., anger/fear). Thus, it could be that mothers have higher expectations for their 4year-olds, and therefore respond in a more non-supportive way to their display of negative emotions, thus viewing their 4-year-olds as less soothable. Importantly, this finding reveals that it may be important to examine 3- and 4-year-olds separately, an age group that has commonly be examined together in the emotion socialization literature. 
In sum, the findings herein support the notion that children's age and gender are influential factors in emotion-related parenting practices (e.g., Kennedy Root \& Denham, 2010). However, it is important to note that I did not find support for the original hypotheses: a negative relation between anger/frustration and supportive reactions to children's anger, and a positive relation between anger/frustration and non-supportive reactions to children's anger. In addition, it was hypothesized there would be a positive relation between soothability and supportive-anger and supportive-fear and a negative relation between soothability and non-supportive anger and nonsupportive fear.

Importantly, previous work has not examined child temperament in conjunction with child gender and age, as they relate to emotion socialization beliefs. Thus, the findings from the current study provide novel information regarding the way child age, child gender, and child temperament affect the emotion socialization process.

\section{Limitations}

While the present study examined an area of research that has rarely been investigated, it is important to note there were several limitations. First, participants included in this study consisted only of mothers, and therefore the results cannot be generalized to other caregivers, including fathers. As noted by Kennedy Root and Denham (2010), mothers and fathers often differ in their reactions to children's emotions; moreover, there are some studies that suggest that mothers and fathers have different functions in the development of children's emotional competence (e.g., Feldman, 2003).

Data were collected via self-report questionnaires, which lends itself to self-bias. Mothers may have answered in what they believed to be socially desirable, thus altering and/or skewing the results. It may be that observations of temperament would have yielded different results, or - perhaps - different ratings of soothability and anger/frustration that mothers 
provided. In addition, the majority of mothers who participated in this study were White or Caucasian, and were middle- to upper-class. Therefore, the characteristics of the participants make it difficult to generalize the findings beyond this sample, as the results could vary among different races, ethnicities, and socioeconomic statuses. In addition, no information was gathered on family composition, so it is unknown if mothers would respond differently to their older or younger children. Lastly, the current study was correlational and not longitudinal, and therefore cannot imply direction of effect.

\section{Future Directions}

This study examined how child temperament influences maternal emotion socialization practices. The hypotheses were drawn from the few studies that have examined the relation between temperament and emotion socialization. However, as stated before, there haven't been any studies to date that have examined the relation between temperament and parents' reactions to specific emotions (e.g., anger and fear). While the analyses examining the relation between temperament and emotion socialization were non-significant, it may be that examining other aspects of temperament and emotion regulatory ability will yield significant results. For instance, it may be that mothers will alter their reactions depending on how well their child regulates a specific affect. This line of research was suggested several years ago (e.g., Underwood, 1997) though few studies have "tackled" it. Thus, it seems that future research should attempt to capture a more in-depth understanding of how children's temperament influences emotion-specific caregiving practices. In addition, further examination of how child age and gender affect the relation between children's temperament and emotion socialization processes would be beneficial.

The vast majority of research in child development involves mothers as influential socialization agents, but very few studies examine fathers. As noted by Kennedy Root and 
Denham (2010), examining fathers as socializers of emotion is important, especially since it has been documented that fathers differ from mothers in their expectations for children's emotional expression (e.g., Brody, 2000) as well as their responses to children's emotions (e.g., Denham et al., 2010). Although we know that mothers and fathers differ in their responses, we know very little about the antecedents for fathers' emotion socialization practices. Thus, this seems to be an important line of study.

On a related note, future studies should also consider examining how temperament affects co-parenting specific to emotion socialization. Cook, Schoppe-Sullivan, Buckley and Davis (2009) examined how child effects influence co-parenting and reported that difficult children had parents who undermined each other's parenting more frequently and intensely, thus negatively impacting their parenting practices. It would be interesting to see how temperament impacts parents' coordination of emotion socialization.

In addition to the need of father's participation, this area of study could benefit in the future by taking both a quantitative and qualitative approach with regards to the measure of emotion socialization. In addition to completing a series of questionnaires regarding children's temperament and emotion-related parenting practices, home and/or laboratory observations of parent-child interactions should be included in future work.

Moreover, future studies should consider the socialization of positive affect. While the purpose of this study was to examine the relation between child temperament and specific emotion socialization beliefs, the study was only focused on children's negative emotions (e.g., anger/fear). It should be priority for future studies to also examine children's positive emotions. For example, rather than examining how children's specific negative emotions of anger and fear influence parents' emotion-related parenting practices, it is equally important to investigate how 
children's positive emotions (e.g., happiness/joy) influence parental emotional socialization processes as well.

\section{Conclusion}

The findings of the present study do provide some support to the notion for child effects (Bell \& Chapman, 1986). However, these effects are moderated by child age and gender. In sum, temperament, child age, and child gender all contribute to mothers' reactions to children's emotions. Further examination of these factors may provide a better understanding of how to best promote the development of children's emotional competence. 
Table 1.

Means and Standard Deviations of Predictor and Outcome Variables

\begin{tabular}{lccccc} 
Variable & $N$ & $M$ & $S D$ & Minimum & Maximum \\
\hline $\begin{array}{l}\text { Predictors } \\
\text { Child Behavior Checklist } \\
\text { Anger/Frustration } \\
\text { Total Sample }\end{array}$ & & & & & \\
Boys & & & & & \\
Girls & 84 & 27.12 & 5.50 & 15.00 & 37.00 \\
3 years & 36 & 27.25 & 6.16 & 15.00 & 37.00 \\
4 years & 48 & 27.02 & 5.02 & 15.00 & 37.00 \\
& 50 & 27.00 & 4.96 & 15.00 & 36.00 \\
Soothability & 34 & 27.29 & 6.29 & 15.00 & 37.00 \\
Total Sample & & & & & \\
Boys & & & & & \\
Girls & 84 & 33.14 & 3.67 & 23.00 & 40.00 \\
3 years & 36 & 32.55 & 3.65 & 24.00 & 40.00 \\
4 years & 48 & 33.58 & 5.02 & 15.00 & 37.00 \\
& 50 & 32.86 & 3.71 & 24.00 & 40.00 \\
& 34 & 33.56 & 3.63 & 23.00 & 39.00
\end{tabular}

Outcomes

CCNES

Supportive anger

Total Sample

$\begin{array}{lllll}84 & 35.30 & 7.65 & 14.00 & 49.00 \\ 36 & 27.25 & 6.16 & 15.00 & 37.00 \\ 48 & 27.02 & 5.02 & 15.00 & 37.00 \\ 50 & 34.28 & 7.91 & 14.00 & 49.00 \\ 34 & 36.79 & 7.10 & 22.00 & 49.00\end{array}$

Non-supportive anger

Total Sample

Boys

$\begin{array}{lllll}84 & 19.60 & 6.79 & 6.00 & 39.00\end{array}$

Girls

$36 \quad 20.75$

7.26

8.00

39.00

48

18.73

6.36

6.00

33.00

3 years

17.80

5.83

6.00

31.00

4 years

3

22.2

$7.32 \quad 8.00$

39.00

Supportive fear

Total Sample

84

67.49

7.44

47.00

77.00

Boys

36

66.50

8.35

48.00

77.00

Girls

68.23

6.6

47.00

77.00

3 years

67.22

$6.92 \quad 50.00$

77.00

4 years

34

67.88

$8.28 \quad 47.00$

77.00 
Non-supportive fear Total Sample

$\begin{array}{lllll}84 & 20.61 & 6.85 & 11.00 & 40.00\end{array}$

Boys

$\begin{array}{lllll}36 & 27.25 & 6.16 & 15.00 & 37.00\end{array}$

Girls

$\begin{array}{lllll}48 & 27.02 & 5.02 & 15.00 & 37.00\end{array}$

3 years

$\begin{array}{lllll}50 & 19.94 & 6.14 & 11.00 & 36.00\end{array}$

4 years

3

$\begin{array}{llll}21.59 & 7.77 & 12.00 & 40.00\end{array}$


Table 2.

Correlations Between Predictor and Outcome Variables - Full Sample

1. $2 . \quad 3 . \quad 4 . \quad 5 . \quad 6$.

Predictors

$C B Q$

$\begin{array}{llllllll}\text { 1. Anger/Frustration } & - & -.19 & .09 & .09 & .08 & .11\end{array}$

$\begin{array}{lllllll}\text { 2. Soothability } & - & .12 & -.06 & .20 & -.13\end{array}$

Outcomes

CCNES

3. Supportive anger $\quad-\quad-.31 * * .63 * *-.30 * *$

4. Non-supportive anger $\quad-\quad-\begin{array}{lll}-.15 & .62 * *\end{array}$

5. Supportive fear $\quad-\quad-.40 * *$

6. Non-supportive fear

Note. $n=84$

$* p<.05 ; * * p<.01$ (1-tailed) 


\section{Table 3.}

Correlations Between Predictor and Outcome Variables - Boys

1.2

3.4

5.

6.

Predictors

$C B Q$

1. Anger/Frustration

$\begin{array}{llllll}- & -.33 * & .18 & -.02 & -.00 & -.05\end{array}$

2. Soothability

$\begin{array}{llllll}- & - & .32 * & -.19 & .41 * * & -.28\end{array}$

Outcomes

CCNES

3. Supportive anger

4. Non-supportive anger

$\begin{array}{llll}- & -.31 * & .66 * * & -.41 * *\end{array}$

5. Supportive fear

- $\quad-.16 \quad .68 * *$

6. Non-supportive fear

Note. $n=36$

$* p<.05 ; * * p<.01$ (1-tailed) 


\section{Table 4.}

Correlations Between Predictor and Outcome Variables - Girls

1.

2.

3.

4.

5. 6.

\section{Predictors}

$C B Q$

1. Anger/Frustration

$\begin{array}{cccccc}- & -.07 & -.02 & .19 & .18 & .27 * \\ & - & -.07 & .08 & -.03 & .00\end{array}$

2. Soothability

Outcomes

CCNES

3. Supportive anger

$\begin{array}{llll}- & -.31 * & .60 * * & -.18\end{array}$

4. Non-supportive anger

$-\quad-.12 \quad .55 * *$

5. Supportive fear

$-\quad-.28^{*}$

6. Non-supportive fear

Note. $n=48$

$* p<.05 ; *^{* *} p<.01$ (1-tailed) 


\section{Table 5.}

Correlations Between Predictor and Outcome Variables - 3-Year-Olds

$1 .-2-3$

4. 5.6.

Predictors

$C B Q$

1. Anger/Frustration

$\begin{array}{llllll}- & -.27 * & .12 & .21 & .01 & .11\end{array}$

2. Soothability

$\begin{array}{lllll}- & .19 & -.08 & .32 * & -.10\end{array}$

Outcomes

CCNES

3. Supportive anger

4. Non-supportive anger

$\begin{array}{llll}- & -.32 * & .58 * * & -.23\end{array}$

5. Supportive fear

$-.16 \quad .57 * *$

6. Non-supportive fear

$-\quad-.40 * *$

Note. $n=50$

$* p<.05 ; * * p<.01$ (1-tailed) 


\section{Table 6.}

Correlations Between Predictor and Outcome Variables - 4-Year-Olds

1.

2.

3.

4.

5.

6.

Predictors

$C B Q$

1. Anger/Frustration

$\begin{array}{llllll}- & -.11 & .06 & -.04 & .14 & .11\end{array}$

2. Soothability

$\begin{array}{lllll}- & -.03 & -.12 & .04 & -.19\end{array}$

Outcomes

CCNES

3. Supportive anger

4. Non-supportive anger

- $\quad-.49 * * .72 * *-.47 * *$

5. Supportive fear

- $\quad-.19 \quad .67 * *$

6. Non-supportive fear

$-\quad-.40 * *$

Note. $n=34$

$* p<.05 ; * * p<.01$ (1-tailed) 


\section{References}

Allport, G. W. (1961). Pattern and growth in personality. New York: Holt, Rinehart and Winston.

Ainsworth, M. S., \& Wittig, B. A. (1969). Attachment and the exploratory behaviour of one-year-olds in a strange situation. In B. M. Foss (Ed.), Determinants of infant behavior (Vol. 4, pp. 113-136), London: Methuen.

Bates, J. E. \& Pettit, G. S. (2007). Temperament, Parenting, and Socialization. In J. E. Grusec, P. D. Hastings, J. E. Grusec \& P. D. Hastings (Eds.), Handbook of socialization: Theory and research. (pp. 153-177). New York: Guilford.

Bell, R.Q. \& Chapman, M. (1986). Child effects in studies using experimental or brief longitudinal approaches to socialization. Developmental Psychology, 22, 595-603.

Brody, L. R. (2000). The socialization of gender differences in emotional expression: Display rules, infant temperament, and differentiation. In A. H. Fischer (Ed.), Gender and emotion: Social psychological perspectives (pp.24-47). Cambridge, UK: Cambridge University Press.

Cook, J. C., Schoppe-Sullivan, S. J., Buckley, C. K., \& Davis, E. F. (2009). Are some children harder to coparent than others? Children's negative emotionality and coparenting relationship quality. Journal of Family Psychology, 23, 606-610.

Crockenberg, S. \& Acredolo, C. (1983). Infant temperament ratings: A function of infants, of mothers, or both? Infant Behavior and Development, 6, 61-72.

Crockenberg, S. \& Leerkes, E.M. (2003). Infant negative emotionality, caregiving, and family relationships. In A.C. Crouter \& A. Booth (Eds.), Children's influence on family dynamics: The neglected side of family relationships (pp.57-78). Mahwah, NJ: Erlbaum. 
Crockenberg, S. \& McCluskey, K. (1986). Change in maternal behavior during the baby's first year of life. Child Development, 57, 746-753.

Denham, S. A. (1998). Emotional development in young children. New York: Guilford.

Denham, S. A., Bassett, H. H., \& Wyatt, T. (2007). The socialization of emotional competence. In J. E. Grusec, P. D. Hastings, J. E. Grusec \& P. D. Hastings (Eds.), Handbook of socialization: Theory and research. (pp. 614-637). New York: Guilford.

Derryberry, D., \& Rothbart, M. K. (1988). Arousal, affect, and attention as components of temperament. Journal of Personality and Social Psychology, 55(6), 958-966.

Eisenberg, N. A., \& Fabes, R. A. (1994). Mothers' reactions to children's negative emotions: Relations to children's temperament and anger behavior. Merrill-Palmer Quarterly, 40, $138-156$.

Eisenberg, N., Cumberland, A., \& Spinrad, T. L. (1998). Parental socialization of emotion. Psychological Inquiry, 9, 241-273.

Eisenberg, N., Fabes, R. A., \& Murphy, B. C. (1996). Parents' reactions to children's negative emotions: Relations to children's social competence and comforting behavior. Child Development, 67(5), 2227-2247.

Erickson, M., Sroufe, L. A., \& Egeland, B. (1985). The relationship between quality of attachment and behavior problems in preschool in a high-risk sample. Monographs of the Society for Research in Child Development, 50, 147-166.

Fabes, R. A., Eisenberg, N. A., \& Bernzweig, J. (1990). The Coping with Children's Negative Emotions Scale. Unpublished document, Arizona State University, Tempe.

Fabes, R. A., Eisenberg, N., Karbon, M., Bernzweig, J., Speer, A. L., \& Carlo, G. (1994). Socialization of children's vicarious emotional responding and prosocial behavior: 
Relations with mothers' perceptions of children's emotional reactivity. Developmental Psychology, 30, 44-55.

Fabes, R. A., Leonard, S. A., Kupanoff, K., \& Martin, C. L. (2001). Parental coping with children's negative emotions: Relations with children's emotional and social responding. Child Development, 72, 907-920.

Fabes, R. A., Poulin, R. E., Eisenberg, N. A., \& Madden-Derdich, D. A. (2002). The Coping with Children's Negative Emotions Scale (CCNES): Psychometric properties and relations with children's emotional competence. Marriage \& Family Review, 34, 285310.

Feldman, R. (2003). Infant-mother and infant-father synchrony: The coregulation of positive arousal, Infant Mental Health Journal, 24, 1-23.

Fivush, R., Brotman, M. A., Buckner, J. P., \& Goodman, S. H. (2000). Gender differences in parent-child emotion narratives. Sex Roles, 42, 233-253.

Goldsmith, H. H. (1996). Studying temperament via construction of the Toddler Behavior Assessment Questionnaire. Child Development, 67, 218-235.

Kennedy Root, A. E., \& Denham, S. A. (2010). The role of gender in the socialization of emotion: Key concepts and critical issues. In A.E. Kennedy \& S.A. Denham (Eds.), New Directions for Child and Adolescent Development: Focus on Gender: Parent and Child Contributions to the Socialization of Emotional Competence. San Francisco: JosseyBass.

Lytton, H. (1991). Different parental practices - Different sources of influence. Behavioral and Brain Sciences, 14, 399-400. 
Malatesta, C. Z., \& Haviland, J. M. (1982). Learning display rules: The socialization of emotion expression in infancy. Child Development, 53, 991-1003.

O'Neal, C. R., \& Magai, C. (2005). Do parents respond in different ways when children feel different emotions? The emotional context of parenting. Development and Psychopathology, 17(2), 467-487.

Paulussen-Hoogeboom, M. C., Stams, G.J. J. M., Hermanns, J. M. A., \& Peetsma, T. T. D. (2008). Relations among child negative emotionality, parenting stress, and maternal sensitive responsiveness in early childhood. Parenting: Science and Practice, 8, 1-16.

Putnam, S., \& Rothbart, M. (2000). Development of Short and Very Short Forms of the Children's Behavior Questionnaire. Journal of Personality Assessment, 87, 102-112.

Rothbart, M. K., \& Derryberry, D. (1981). Development of individual differences in temperament. In M. E. Lamb \& A. L. Brown (Eds.), Advances in developmental psychology (Vol. 1, pp. 37-86). Hillsdale, NJ: Erlbaum.

Rothbart, M.K. \& Bates, J.E. (1998). Temperament. In N. Eisenberg (Ed.), Social, emotional, and personality development: Vol. 3. Handbook of child psychology (pp. 100-151). New York: Wiley.

Saarni, C., Mumme, D., \& Campos, J. J. (1998). Emotional development: Action, communication, and understanding. In W. Damon (Series Ed.) \& N. Eisenberg (Vol. Ed.), Handbook of child psychology: Vol. 3. Social, emotional, and personality development (5th ed., pp. 237-309). New York: Wiley.

Slater, M. A., \& Power, T. G. (1987). Multidimensional assessment of parenting in single-parent families. In J. P. Vincent (Ed.), Advances in family intervention, assessment, and theory (pp. 19-228). Greenwich, CT: JAI Press. 
Thomas, A., \& Chess, S. (1977). Temperament and development. New York: New York University Press.

Underwood, M.K. (1997). Top ten pressing questions about the development of emotion regulation. Motivation and Emotion, 21, 127-146.

van den Akker, A., Deković, M., Prinzie, P. \& Asscher, J.J. (2010). Toddlers' temperament profiles: Stability and relations to negative and positive parenting. J Abnorm Child Psychology, 38, 485-495. 


\section{Appendix A}

\section{Facebook Ad}

\section{ATTENTION MOTHERS OF PRESCHOOL-AGED CHILDREN:}

If you are the mother of a preschooler, you are eligible to participate in an exciting research study on emotion socialization (approved by WVU Human Subjects IRB). If you choose to participate, you can enter for a chance to win one of four $\$ 25.00$ gift cards. This study involves the completion of questionnaires and will take approximately 20 minutes for you to complete. 


\section{Appendix B}

\section{Cover Page}

Thank you for considering participation in our research. This research project was designed to examine how child temperament influences maternal emotion socialization in preschool-aged children. This project is being conducted by Amy E. Root, Ph.D and Stephanie Clarke, B.S. in the Department of Technology, Learning and Culture. Your participation in this project is greatly appreciated and will take approximately 20 minutes to fill out the attached questionnaires. You may opt-in to a raffle to win one of four $\$ 25.00$ gift cards. There is more information about the study below.

Study Title: Child Temperament as an Influence on Maternal Emotion Socialization in Preschool-Aged Children

Investigator: Root, Amy E.

Co-Investigator(s): Clarke, Stephanie

Contact Persons: In the event you experience any side effects or injury related to this research, you should contact Dr. Amy E. (Kennedy) Root at 304-293-0380.

If you have any questions, concerns, or complaints about this research, you can contact Dr. Amy E. (Kennedy) Root at 304-293-0380. In addition, if you would like to discuss problems, concerns, have suggestions related to research, or would like to offer input about the research, contact the Office of Research Integrity and Compliance at 304-293-7073.

Introduction \& Purpose: You have been asked to participate in this research study to examine how child temperament influences maternal emotion socialization in preschool-aged children. This project is being conducted by Amy E. Root, Ph.D and Stephanie Clarke, B.S. in the Department of Technology, Learning and Culture. Your participation in this project is greatly appreciated and will take approximately 20 minutes to fill out the attached questionnaires.

This study is being conducted by Dr. Amy E. Root, Ph.D. and Stephanie Clarke, B.S. in the Department of Technology, Learning \& Culture at West Virginia University. This research is being conducted to fulfill the requirements for a master's thesis in Educational Psychology in the Department of Technology, Learning \& Culture at West Virginia University, under the supervision of Dr. Amy E. Root.

Description of Procedures: This study involves the completion of questionnaires and will take approximately 20 minutes for you to complete. You will be asked to fill out three questionnaires (one basic demographic questionnaire, one questionnaire about child temperament, and one questionnaire about parenting related to emotion). You do not have to answer all the questions. You will have the opportunity to see the questionnaire before participating. To see the questionnaires prior to consenting, please contact the PI via e-mail 
(Amy.Kennedy@mail.wvu.edu) or telephone (304) 293-0380.

Risks and Discomforts: There are no known or expected risks from participating in this study, except for the mild frustration associated with answering the questions.

Benefits: You may not receive any direct benefit from this study. The knowledge gained from this study may eventually benefit others.

Confidentiality: Participation in this study is voluntary. You are free to withdraw your consent to participate in this study at any time. Refusal to participate or withdrawal will involve no penalty to you. In the event new information becomes available that may affect your willingness to participate in this study, this information will be given to you so that you can make an informed decision about whether or not to continue your participation

Financial Considerations: You may opt to be entered into a raffle for completion of these surveys. Instructions on how to enter the raffle follow the questionnaires. 
Appendix C

Demographic Information

Child's Birthdate Child's Age

Month Day Year

Child's Sex (circle one):

MALE

FEMALE

\section{Child's Country of Birth}

Is your child biological?

Adopted? Foster child?

\section{Child's Ethnicity (circle one):}

Hispanic or Latino

Not Hispanic or Latino

Child's Race (check one):

American Indian/Alaska Native

Asian

Black or African American

Native Hawaiian or Other Pacific Islander

White or Caucasian

Bi- or Multi-racial (please specify):

Other (please specify): 
Mother's Birthdate

Age

Month Day Year

\section{Occupation}

Mother's employment status:

Employed full-time

Employed part-time

Not employed outside of home

Retired

Unemployed

Other (specify)

Mother's education level:

Elementary School

High School

Vocational School

Some College

University Degree

Some Graduate School

Master's Degree

Doctoral Degree

Other (specify) 
If mother was not born in the U.S., how long has she been residing in the U.S.?

0 to 1 year

5 to 10 years
1 to 3 years

over 10 years
3 to 5 years

Other

Mother's Ethnicity (circle one):

Hispanic or Latino

Not Hispanic or Latino

\section{Mother's Race (check one):}

American Indian/Alaska Native

Asian

Black or African American

Native Hawaiian or Other Pacific Islander

White or Caucasian

Bi- or Multi-racial (please specify):

Other (please specify):

What language is spoken most often in your home?

English

Filipino

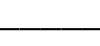

Malaysian
Chinese

Japanese

Other (specify)
Spanish

Korean 


$\begin{array}{lll}\text { Mother's Marital Status with } & \text { Married _ How long? } \\ \text { Child's father (check one): } & \text { Separated } & \text { How long? } \\ & \text { Divorced _ How long? } \\ & \text { Common law _ } \\ & \text { Other (specify) }\end{array}$

Mother's current relationship status (check one): Married

Separated

Divorced

Common law

Single

Living with partner

Other (specify)

Child's Father's Birthdate Age

Month Day $\quad$ Year

Occupation

What is the father's employment status: Employed full-time

Employed part-time

Not employed outside of home

Retired

Unemployed

Other (specify) 
High School

Vocational School

Some College

University Degree

Some Graduate School

Master's Degree

Doctoral Degree

Other (specify)

Father's country of birth

If father was not born in the U.S., how long has he been residing in the U.S.?

0 to 1 year

5 to 10 years
1 to 3 years

over 10 years
3 to 5 years

Other

\section{Father's Ethnicity (circle one):}

Hispanic or Latino

Not Hispanic or Latino

\section{Father's Race (check one):}

American Indian/Alaska Native

Asian 
Black or African American

Native Hawaiian or Other Pacific Islander

White or Caucasian

Bi- or Multi-racial (please specify):

Other (please specify):

$\begin{array}{lll}\text { Father's Marital Status with } & \text { Married _ How long? } \\ \text { Child's mother (check one): } & \text { Separated __ How long? } \\ & \text { Divorced _ How long? } \\ & \text { Common law __ } \\ & \text { Other (specify) }\end{array}$

Father's current relationship status (check one): Married

Separated

Divorced

Common law

Single

Living with partner

Other (specify)

Household Income (circle one):

Less than $\$ 10,000$

$\$ 75,000-\$ 100,000$

$\$ 10,000-\$ 25,000$

$\$ 100,000$ - \$150,000

$\$ 25,000-\$ 50,000$

Greater than $\$ 150,000$

$\$ 50,000-\$ 75,000$ 


\section{Appendix D}

\section{Child's Behavior Questionnaire}

\section{Short Form Version 1}

Subject No.

Today's Date

$\longrightarrow$

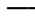




$\begin{array}{ll}3 & \text { slightly untrue of your child } \\ 4 & \text { neither true nor false of your child } \\ 5 & \text { slightly true of your child } \\ 6 & \text { quite true of your child } \\ 7 & \text { extremely true of your child }\end{array}$

If you cannot answer one of the items because you have never seen the child in that situation, for example, if the statement is about the child's reaction to your singing and you have never sung to your child, then circle NA (not applicable).

Please be sure to circle a number or NA for every item. 
1. Seems always in a big hurry to get from one place to another.

$\begin{array}{llllllll}1 & 2 & 3 & 4 & 5 & 6 & 7 & \text { NA }\end{array}$

2. Gets angry when told s/he has to go to bed.

$\begin{array}{llllllll}1 & 2 & 3 & 4 & 5 & 6 & 7 & \text { NA }\end{array}$

3. Is not very bothered by pain.

$\begin{array}{llllllll}1 & 2 & 3 & 4 & 5 & 6 & 7 & \text { NA }\end{array}$

4. Likes going down high slides or other adventurous activities.

$\begin{array}{llllllll}1 & 2 & 3 & 4 & 5 & 6 & 7 & \text { NA }\end{array}$

5. Notices the smoothness or roughness of objects s/he touches.

$\begin{array}{llllllll}1 & 2 & 3 & 4 & 5 & 6 & 7 & \text { NA }\end{array}$

6. Gets so worked up before an exciting event that s/he has trouble sitting still.

$\begin{array}{llllllll}1 & 2 & 3 & 4 & 5 & 6 & 7 & \mathrm{NA}\end{array}$

7. Usually rushes into an activity without thinking about it.

$\begin{array}{llllllll}1 & 2 & 3 & 4 & 5 & 6 & 7 & \mathrm{NA}\end{array}$

8. Cries sadly when a favorite toy gets lost or broken.

$\begin{array}{llllllll}1 & 2 & 3 & 4 & 5 & 6 & 7 & \text { NA }\end{array}$

9. Becomes quite uncomfortable when cold and/or wet.

$\begin{array}{llllllll}1 & 2 & 3 & 4 & 5 & 6 & 7 & \text { NA }\end{array}$

10. Likes to play so wild and recklessly that s/he might get hurt.

$\begin{array}{llllllll}1 & 2 & 3 & 4 & 5 & 6 & 7 & \mathrm{NA}\end{array}$

11. Seems to be at ease with almost any person.

$\begin{array}{llllllll}1 & 2 & 3 & 4 & 5 & 6 & 7 & \text { NA }\end{array}$


12. Tends to run rather than walk from room to room.

$\begin{array}{llllllll}1 & 2 & 3 & 4 & 5 & 6 & 7 & \mathrm{NA}\end{array}$

13. Notices it when parents are wearing new clothing.

$\begin{array}{llllllll}1 & 2 & 3 & 4 & 5 & 6 & 7 & \text { NA }\end{array}$

14. Has temper tantrums when $\mathrm{s} / \mathrm{he}$ doesn't get what s/he wants.

$\begin{array}{llllllll}1 & 2 & 3 & 4 & 5 & 6 & 7 & \text { NA }\end{array}$

15. Gets very enthusiastic about the things s/he does

$\begin{array}{llllllll}1 & 2 & 3 & 4 & 5 & 6 & 7 & \text { NA }\end{array}$

16. When practicing an activity, has a hard time keeping her/his mind on it.

$\begin{array}{llllllll}1 & 2 & 3 & 4 & 5 & 6 & 7 & \text { NA }\end{array}$

17. Is afraid of burglars or the "boogie man."

$\begin{array}{llllllll}1 & 2 & 3 & 4 & 5 & 6 & 7 & \text { NA }\end{array}$

18. When outside, often sits quietly.

$\begin{array}{llllllll}1 & 2 & 3 & 4 & 5 & 6 & 7 & \text { NA }\end{array}$

19. Enjoys funny stories but usually doesn't laugh at them.

$\begin{array}{llllllll}1 & 2 & 3 & 4 & 5 & 6 & 7 & \text { NA }\end{array}$

20. Tends to become sad if the family's plans don't work out.

$\begin{array}{llllllll}1 & 2 & 3 & 4 & 5 & 6 & 7 & \text { NA }\end{array}$

21. Will move from one task to another without completing any of them.

$\begin{array}{llllllll}1 & 2 & 3 & 4 & 5 & 6 & 7 & \mathrm{NA}\end{array}$

22. Moves about actively (runs, climbs, jumps) when playing in the house.

$\begin{array}{llllllll}1 & 2 & 3 & 4 & 5 & 6 & 7 & \text { NA }\end{array}$


23. Is afraid of loud noises.

$\begin{array}{llllllll}1 & 2 & 3 & 4 & 5 & 6 & 7 & \mathrm{NA}\end{array}$

24. Seems to listen to even quiet sounds.

$\begin{array}{llllllll}1 & 2 & 3 & 4 & 5 & 6 & 7 & \text { NA }\end{array}$

25. Has a hard time settling down after an exciting activity.

$\begin{array}{llllllll}1 & 2 & 3 & 4 & 5 & 6 & 7 & \text { NA }\end{array}$

26. Enjoys taking warm baths.

$\begin{array}{lllllllll}1 & 2 & 3 & 4 & 5 & 6 & 7 & \text { NA }\end{array}$

27. Seems to feel depressed when unable to accomplish some task.

$\begin{array}{lllllllll}1 & 2 & 3 & 4 & 5 & 6 & 7 & \text { NA }\end{array}$

28. Often rushes into new situations.

$\begin{array}{lllllllll}1 & 2 & 3 & 4 & 5 & 6 & 7 & \text { NA }\end{array}$

29. Is quite upset by a little cut or bruise.

$\begin{array}{llllllll}1 & 2 & 3 & 4 & 5 & 6 & 7 & \mathrm{NA}\end{array}$

30. Gets quite frustrated when prevented from doing something s/he wants to do.

$\begin{array}{llllllll}1 & 2 & 3 & 4 & 5 & 6 & 7 & \text { NA }\end{array}$

31. Becomes upset when loved relatives or friends are getting ready to leave following a visit.

$\begin{array}{llllllll}1 & 2 & 3 & 4 & 5 & 6 & 7 & \text { NA }\end{array}$

32. Comments when a parent has changed his/her appearance.

$\begin{array}{lllllllll}1 & 2 & 3 & 4 & 5 & 6 & 7 & \mathrm{NA}\end{array}$

33. Enjoys activities such as being chased, spun around by the arms, etc.

$\begin{array}{lllllllll}1 & 2 & 3 & 4 & 5 & 6 & 7 & \text { NA }\end{array}$


34. When angry about something, s/he tends to stay upset for ten minutes or longer.

$\begin{array}{llllllll}1 & 2 & 3 & 4 & 5 & 6 & 7 & \text { NA }\end{array}$

35. Is not afraid of the dark.

$\begin{array}{llllllll}1 & 2 & 3 & 4 & 5 & 6 & 7 & \text { NA }\end{array}$

36. Takes a long time in approaching new situations.

$\begin{array}{llllllll}1 & 2 & 3 & 4 & 5 & 6 & 7 & \text { NA }\end{array}$

37. Is sometimes shy even around people s/he has known a long time.

$\begin{array}{llllllll}1 & 2 & 3 & 4 & 5 & 6 & 7 & \text { NA }\end{array}$

38. Can wait before entering into new activities if $\mathrm{s} / \mathrm{he}$ is asked to.

$\begin{array}{llllllll}1 & 2 & 3 & 4 & 5 & 6 & 7 & \text { NA }\end{array}$

39. Enjoys "snuggling up" next to a parent or babysitter.

$\begin{array}{llllllll}1 & 2 & 3 & 4 & 5 & 6 & 7 & \text { NA }\end{array}$

40. Gets angry when s/he can't find something s/he wants to play with.

$\begin{array}{llllllll}1 & 2 & 3 & 4 & 5 & 6 & 7 & \text { NA }\end{array}$

41. Is afraid of fire.

$\begin{array}{llllllll}1 & 2 & 3 & 4 & 5 & 6 & 7 & \text { NA }\end{array}$

42. Sometimes seems nervous when talking to adults s/he has just met.

$\begin{array}{llllllll}1 & 2 & 3 & 4 & 5 & 6 & 7 & \text { NA }\end{array}$

43. Is slow and unhurried in deciding what to do next.

$\begin{array}{llllllll}1 & 2 & 3 & 4 & 5 & 6 & 7 & \text { NA }\end{array}$

44. Changes from being upset to feeling much better within a few minutes.

$\begin{array}{llllllll}1 & 2 & 3 & 4 & 5 & 6 & 7 & \text { NA }\end{array}$


45. Prepares for trips and outings by planning things s/he will need..

$\begin{array}{llllllll}1 & 2 & 3 & 4 & 5 & 6 & 7 & \text { NA }\end{array}$

46. Becomes very excited while planning for trips.

$\begin{array}{llllllll}1 & 2 & 3 & 4 & 5 & 6 & 7 & \text { NA }\end{array}$

47. Is quickly aware of some new item in the living room.

$\begin{array}{llllllll}1 & 2 & 3 & 4 & 5 & 6 & 7 & \text { NA }\end{array}$

48. Hardly ever laughs out loud during play with other children.

$\begin{array}{llllllll}1 & 2 & 3 & 4 & 5 & 6 & 7 & \text { NA }\end{array}$

49. Is not very upset at minor cuts or bruises.

$\begin{array}{llllllll}1 & 2 & 3 & 4 & 5 & 6 & 7 & \text { NA }\end{array}$

50. Prefers quiet activities to active games.

$\begin{array}{llllllll}1 & 2 & 3 & 4 & 5 & 6 & 7 & \text { NA }\end{array}$

51. Tends to say the first thing that comes to mind, without stopping to think about it.

$\begin{array}{llllllll}1 & 2 & 3 & 4 & 5 & 6 & 7 & \text { NA }\end{array}$

52. Acts shy around new people.

$\begin{array}{llllllll}1 & 2 & 3 & 4 & 5 & 6 & 7 & \text { NA }\end{array}$

53. Has trouble sitting still when s/he is told to (at movies, church, etc.).

$\begin{array}{llllllll}1 & 2 & 3 & 4 & 5 & 6 & 7 & \text { NA }\end{array}$

54. Rarely cries when s/he hears a sad story.

$\begin{array}{llllllll}1 & 2 & 3 & 4 & 5 & 6 & 7 & \text { NA }\end{array}$

55. Sometimes smiles or giggles playing by her/himself.

$\begin{array}{llllllll}1 & 2 & 3 & 4 & 5 & 6 & 7 & \text { NA }\end{array}$


56. Rarely becomes upset when watching a sad event in a TV show.

$\begin{array}{llllllll}1 & 2 & 3 & 4 & 5 & 6 & 7 & \text { NA }\end{array}$

57. Enjoys just being talked to.

$\begin{array}{llllllll}1 & 2 & 3 & 4 & 5 & 6 & 7 & \text { NA }\end{array}$

58. Becomes very excited before an outing (e.g., picnic, party).

$\begin{array}{llllllll}1 & 2 & 3 & 4 & 5 & 6 & 7 & \text { NA }\end{array}$

59. If upset, cheers up quickly when s/he thinks about something else.

$\begin{array}{llllllll}1 & 2 & 3 & 4 & 5 & 6 & 7 & \text { NA }\end{array}$

60. Is comfortable asking other children to play.

$\begin{array}{llllllll}1 & 2 & 3 & 4 & 5 & 6 & 7 & \text { NA }\end{array}$

61. Rarely gets upset when told s/he has to go to bed.

$\begin{array}{llllllll}1 & 2 & 3 & 4 & 5 & 6 & 7 & \text { NA }\end{array}$

62. When drawing or coloring in a book, shows strong concentration.

$\begin{array}{llllllll}1 & 2 & 3 & 4 & 5 & 6 & 7 & \text { NA }\end{array}$

63. Is afraid of the dark.

$\begin{array}{llllllll}1 & 2 & 3 & 4 & 5 & 6 & 7 & \text { NA }\end{array}$

64. Is likely to cry when even a little bit hurt.

$\begin{array}{llllllll}1 & 2 & 3 & 4 & 5 & 6 & 7 & \text { NA }\end{array}$

65. Enjoys looking at picture books.

$\begin{array}{llllllll}1 & 2 & 3 & 4 & 5 & 6 & 7 & \text { NA }\end{array}$

66. Is easy to soothe when s/he is upset.

$\begin{array}{llllllll}1 & 2 & 3 & 4 & 5 & 6 & 7 & \text { NA }\end{array}$


67. Is good at following instructions.

$\begin{array}{llllllll}1 & 2 & 3 & 4 & 5 & 6 & 7 & \mathrm{NA}\end{array}$

68. Is rarely frightened by "monsters" seen on TV or at movies.

$\begin{array}{llllllll}1 & 2 & 3 & 4 & 5 & 6 & 7 & \text { NA }\end{array}$

69. Likes to go high and fast when pushed on a swing.

$\begin{array}{llllllll}1 & 2 & 3 & 4 & 5 & 6 & 7 & \text { NA }\end{array}$

70. Sometimes turns away shyly from new acquaintances.

$\begin{array}{llllllll}1 & 2 & 3 & 4 & 5 & 6 & 7 & \text { NA }\end{array}$

71. When building or putting something together, becomes very involved in what $\mathrm{s} / \mathrm{he}$ is doing, and works for long periods.

$\begin{array}{llllllll}1 & 2 & 3 & 4 & 5 & 6 & 7 & \text { NA }\end{array}$

72. Likes being sung to.

$\begin{array}{llllllll}1 & 2 & 3 & 4 & 5 & 6 & 7 & \text { NA }\end{array}$

73. Approaches places s/he has been told are dangerous slowly and cautiously.
$\begin{array}{llllllll}1 & 2 & 3 & 4 & 5 & 6 & 7 & \text { NA }\end{array}$

74. Rarely becomes discouraged when s/he has trouble making something work.

$\begin{array}{llllllll}1 & 2 & 3 & 4 & 5 & 6 & 7 & \text { NA }\end{array}$

75. Is very difficult to soothe when s/he has become upset.

$\begin{array}{llllllll}1 & 2 & 3 & 4 & 5 & 6 & 7 & \text { NA }\end{array}$

76. Likes the sound of words, such as nursery rhymes.

$\begin{array}{llllllll}1 & 2 & 3 & 4 & 5 & 6 & 7 & \text { NA }\end{array}$

77. Smiles a lot at people s/he likes.

$\begin{array}{llllllll}1 & 2 & 3 & 4 & 5 & 6 & 7 & \text { NA }\end{array}$


78. Dislikes rough and rowdy games.

$\begin{array}{llllllll}1 & 2 & 3 & 4 & 5 & 6 & 7 & \text { NA }\end{array}$

79. Often laughs out loud in play with other children.

$\begin{array}{llllllll}1 & 2 & 3 & 4 & 5 & 6 & 7 & \text { NA }\end{array}$

80. Rarely laughs aloud while watching TV or movie comedies.

$\begin{array}{llllllll}1 & 2 & 3 & 4 & 5 & 6 & 7 & \text { NA }\end{array}$

81. Can easily stop an activity when s/he is told "no."

$\begin{array}{llllllll}1 & 2 & 3 & 4 & 5 & 6 & 7 & \text { NA }\end{array}$

82. Is among the last children to try out a new activity.

$\begin{array}{llllllll}1 & 2 & 3 & 4 & 5 & 6 & 7 & \text { NA }\end{array}$

83. Doesn't usually notice odors such as perfume, smoke, cooking, etc.

$\begin{array}{llllllll}1 & 2 & 3 & 4 & 5 & 6 & 7 & \text { NA }\end{array}$

84. Is easily distracted when listening to a story.

$\begin{array}{llllllll}1 & 2 & 3 & 4 & 5 & 6 & 7 & \text { NA }\end{array}$

85. Is full of energy, even in the evening.

$\begin{array}{llllllll}1 & 2 & 3 & 4 & 5 & 6 & 7 & \text { NA }\end{array}$

86. Enjoys sitting on parent's lap.

$\begin{array}{llllllll}1 & 2 & 3 & 4 & 5 & 6 & 7 & \text { NA }\end{array}$

87. Gets angry when called in from play before s/he is ready to quit.

$\begin{array}{llllllll}1 & 2 & 3 & 4 & 5 & 6 & 7 & \text { NA }\end{array}$

88. Enjoys riding a tricycle or bicycle fast and recklessly.

$\begin{array}{llllllll}1 & 2 & 3 & 4 & 5 & 6 & 7 & \text { NA }\end{array}$


89. Sometimes becomes absorbed in a picture book and looks at it for a long time.

$\begin{array}{llllllll}1 & 2 & 3 & 4 & 5 & 6 & 7 & \text { NA }\end{array}$

90. Remains pretty calm about upcoming desserts like ice cream.

$\begin{array}{llllllll}1 & 2 & 3 & 4 & 5 & 6 & 7 & \text { NA }\end{array}$

91. Hardly ever complains when ill with a cold.

$\begin{array}{lllllllll}1 & 2 & 3 & 4 & 5 & 6 & 7 & \text { NA }\end{array}$

92. Looks forward to family outings, but does not get too excited about them.

$\begin{array}{llllllll}1 & 2 & 3 & 4 & 5 & 6 & 7 & \text { NA }\end{array}$

93. Likes to sit quietly and watch people do things.

$\begin{array}{llllllll}1 & 2 & 3 & 4 & 5 & 6 & 7 & \text { NA }\end{array}$

94. Enjoys gentle rhythmic activities, such as rocking or swaying.

$\begin{array}{llllllll}1 & 2 & 3 & 4 & 5 & 6 & 7 & \text { NA }\end{array}$

Please check back to make sure you have completed all the pages of the questionnaire. Thank you very much for your help! 


\section{Appendix E}

\section{Parent Attitude/Behavior Questionnaire}

\section{Adapted Version of Coping with Children's Negative Emotions Scale}

Instructions: In the following items, please indicate on a scale from 1 (very unlikely) to 7 (very likely) the likelihood that you would respond in the ways listed for each item. Please read each item carefully and respond as honestly and sincerely as you can. For each response, please circle a number from 1-7.

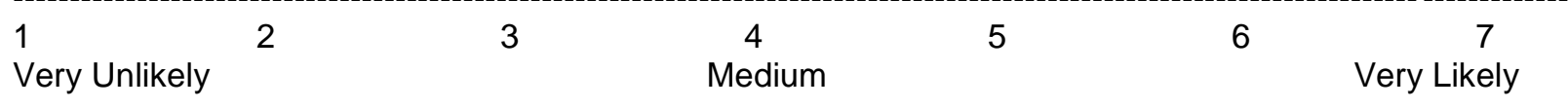

\section{If my child becomes angry because he/she is unable to go to his/her friend's birthday party, I} would:

a. send my child to his/her room to cool off

1234567

b. get angry at my child

c. help my child think about ways that he/she can still be with

friends (e.g., invite some friends over after the party)

1234567

d. tell my child not to make a big deal out of missing the party

1234567

e. encourage my child to express his/her feelings of

anger and frustration

1234567

f. soothe my child and do something fun with him/her to make

him/her feel better about missing the party

1234567

g. Any other reaction?

2. If my child breaks his/her new bike, and then gets upset and cries, I would:

a. remain calm and not let myself get anxious

b. comfort my child and try to get him/her to forget

about the accident

1234567

c. tell my child that he/she is over-reacting

1234567

d. help my child figure out how to get the bike fixed

1234567

e. tell my child it's OK to cry

1234567

f. tell my child to stop crying or he/she won't be

allowed to ride his/her bike anytime soon

1234567

g. Any other reaction?

3. If my child loses some prized possession (stuffed animal) and reacts with tears, I would:

a. get upset with him/her for being so careless and

then crying about it

1234567

b. tell my child that he/she is over-reacting

1234567

c. help my child think of places he/she hasn't looked yet

1234567

d. distract my child by talking about happy things

1234567

e. tell him/her it's OK to cry when you feel unhappy

1234567

f. tell him/her that's what happens when you're not careful

1234567

g. Any other reaction? 
4. If my child is afraid of injections and becomes quite shaky and teary while waiting for his/her turn to get a shot, I would:

a. tell him/her to shape up or he/she won't be allowed

to do something he/she likes to do (e.g., watch TV)

1234567

b. encourage my child to talk about his/her fears

1234567

c. tell my child not to make big deal of the shot

1234567

d. tell him/her not to embarrass us by crying

1234567

e. comfort him/her before and after the shot

1234567

f. talk to my child about ways to make it hurt less

(such as relaxing so it won't hurt or taking deep breaths).

g. Any other reaction?

1234567

$\begin{array}{llcccc}1 & 2 & 3 & 4 & 6 & 7 \\ \text { Very Unlikely } & & \text { Medium } & & \text { Very Likely }\end{array}$

5. If my child is going over to spend the afternoon at a friend's house and becomes nervous and upset because I can't stay there with him/her, I would:

a. distract my child by talking about all the fun he/she will

have with his/her friend

b. help my child think of things that he/she could do so that

being at the friend's house without me wasn't scary

(e.g., take a favorite book or toy with him/her)

1234567

c. tell my child to quit over-reacting and being a baby

1234567

d. tell the child that if he/she doesn't stop that he/she

1234567

won't be allowed to go out anymore

1234567

e. feel upset and uncomfortable because of my child's reactions

1234567

f. encourage my child to talk about his/her nervous feelings

g. Any other reaction?

6. If my child is participating in some group activity with his/her friends and proceeds to make a mistake and then looks embarrassed and on the verge of tears, I would:

a. comfort my child and try to make him/her feel better

1234567

b. tell my child that he/she is over-reacting

c. feel uncomfortable and embarrassed myself

1234567

d. tell my child to straighten up or we'll go home right away

1234567

e. encourage my child to talk about his/her feelings

of embarrassment

1234567

f. tell my child that I'll help him/her practice so that

he/she can do better next time

1234567

g. Any other reaction?

1234567 
7. If my child is about to appear in a recital or sports activity and becomes visibly nervous about people watching him/her, I would:

a. help my child think of things that he/she could do to get ready for his/her turn (e.g., to do some warm-ups and not to look at the audience)

b. suggest that my child think about something relaxing

so that his/her nervousness will go away

c. remain calm and not get nervous myself

1234567

1234567

d. tell my child that he/she is being a baby about it

1234567

e. tell my child that if he/she doesn't calm down, we'll

have to leave and go home right away

f. encourage my child to talk about his/her nervous feelings

1234567

g. Any other reaction?

1234567

8. If my child receives an undesirable birthday gift from a friend and looks obviously disappointed, even annoyed, after opening it in the presence of the friend, I would:

a. encourage my child to express his/her disappointed feelings

1234567

b. tell my child that the present can be exchanged

for something the child wants

c. NOT be annoyed with my child for being rude

1234567

d. tell my child that he/she is over-reacting

1234567

e. scold my child for being insensitive to the

1234567

friend's feelings

1234567

f. try to get my child to feel better by doing something fun

1234567

g. Any other reaction?

$\begin{array}{llcccc}1 & 2 & 3 & 4 & 5 & 6 \\ \text { Very Unlikely } & & & \text { Medium } & & \text { Very Likely }\end{array}$

9. If my child is panicky and can't go to sleep after watching a scary TV show, I would:

a. encourage my child to talk about what scared him/her

1234567

b. get upset with him/her for being silly

c. tell my child that he/she is over-reacting

1234567

d. help my child think of something to do so that he/she can get

to sleep (e.g., take a toy to bed, leave the lights on)

1234567

e. tell him/her to go to bed or he/she won't be allowed to watch any more TV

1234567

f. do something fun with my child to help him/her forget

about what scared him/her

g. Any other reaction? 
10. If my child is at a park and appears on the verge of tears because the other children are mean to him/her and won't let him/her play with them, I would:

a. NOT get upset myself

b. tell my child that if he/she starts crying

then we'll have to go home right away

1234567

c. tell my child it's OK to cry when he/she feels bad

1234567

d. comfort my child and try to get him/her to think about

1234567

something happy

1234567

my child think of something else to do

1234567

g. Any other reaction?

11. If my child is playing with other children and one of them calls him/her names, and my child then begins to tremble and become tearful, I would:

a. tell my child not to make a big deal out of it

1234567

b. feel upset myself

1234567

c. tell my child to behave or we'll have to go home right away

1234567

d. help my child think of constructive things to do when

other children tease him/her (e.g., find other things to do)

1234567

e. comfort him/her and play a game to take his/her mind off

the upsetting event

1234567

f. encourage him/her to talk about how it hurts to be teased

1234567

g. Any other reaction?

12. If my child is shy and scared around strangers and consistently becomes teary and wants to stay in his/her bedroom whenever family friends and their children come to visit, I would:

a. help my child think of things to do that would make meeting

my friends less scary (e.g., to take a favorite toy with

him/her when meeting my friends)

1234567

b. tell my child that it is OK to feel nervous

1234567

c. try to make my child happy by talking about the fun

things we can do with our friends

1234567

d. feel upset and uncomfortable because of my child's reactions

1234567

e. tell my child that he/she must stay in the living room

and visit with our friends

1234567

f. tell my child that he/she is being a baby

1234567

g. Any other reaction? 


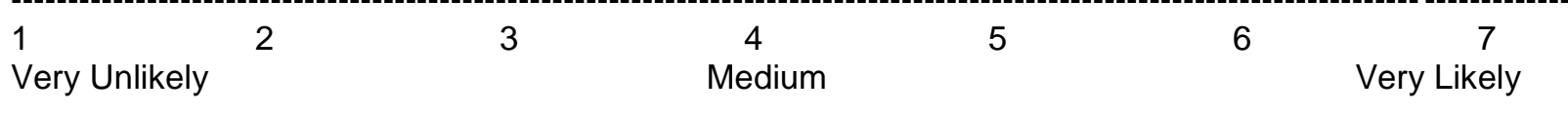

13. It is $\mathbf{1 5}$ minutes until dinner is ready. Your child asks for a cookie because she/he is "starving." You explain that dinner will be ready in 15 minutes and that she/he will have to wait until then. Your child yells and stomps his or her feet continuously. I would:
a. punish him/her for his/her behavior
1234567
b. get angry for his/her overreaction
1234567
c. tell my child that he/she is over-reacting
1234567
d. help my child think of something to do so that he/she can get
keep occupied until dinner
1234567
e. tell my child that it's o.k. to feel angry, but s/he will have to wait for dinner
1234567
f. comfort my child by offering an alternate healthy snack (e.g., carrots)
1234567
g. Any other reaction?

14. You and your child are in a toy store. Your child asks you to buy him/her a new toy. You tell your child no, that she/he just received several new toys at her/his birthday party, and then you go to leave the store. Your child throws her/himself onto the floor kicking and screaming, yelling that she/he wants the toy. Your child will not leave the store. I would:
a. NOT get upset myself
b. tell my child that if he/she will be punished when you get home
c. tell my child it's OK to be anger, but they need to calm down
d. comfort my child and suggest to him/her how to calm down
(e.g., count to five; deep breaths)
e. distract my child by reminding him/her of another fun activity
s/he'll be doing later in the day/week
f. tell my child to stop acting like a baby
g. Any other reaction?

1234567

1234567

1234567

1234567

1234567

1234567

15. You've moved into a new neighborhood, and your child is invited to a birthday party being held for the child next door. You take your child to the party and stay awhile. You notice that your child looks very nervous and uncomfortable, and is keeping to her/himself.
a. tell my child not to make a big deal out of it
b. feel upset myself and uncomfortable because of my child's reactions
1234567
c. tell my child that $\mathrm{s} /$ he must remain at the party
d. help my child think of constructive things to do to feel more comfortable
1234567
1234567
1234567
e. tell my child s/he is being a baby
1234567
f. tell my child it's OK to be nervous
1234567

g. Any other reaction?

16. Your child has a race with friends in the neighborhood, comes in first, and is very excited. When you get home, for a long time, your child continues to jump around gleefully and exclaim to you about her/his victory.
a. praise my child for his/her accomplishment, encourage him/her to celebrate
1234567
b. tell my child that it is OK to feel happy
c. point out my child's accomplishment, and tell him/her I am proud of him/her
1234567
1234567
d. feel uncomfortable because of my child's jubilant behavior
1234567
e. tell my child that it's not that big of a deal, and to calm down
1234567
f. tell my child to calm down or they'll get a time out
1234567

g. Any other reaction? 
17. It is your sister's birthday and she has invited the whole family to celebrate by going out for dinner. The restaurant she has chosen is rather elegant and formal. During the dinner your child exuberantly jumps out of his/her chair and shouts, "Happy birthday, Auntie!"
a. Encourage him/her to celebrate
1234567
b. tell my child that it is OK to feel happy
1234567
c. point out that my child's reaction was thoughtful, and tell him/her I am proud of him/her 1234567
d. feel uncomfortable because of my child's jubilant behavior
1234567
e. tell my child to calm down
1234567
f. tell my child to calm down or they won't get any birthday cake
1234567

g. Any other reaction?

When your child displays ANGER how does it make you feel?

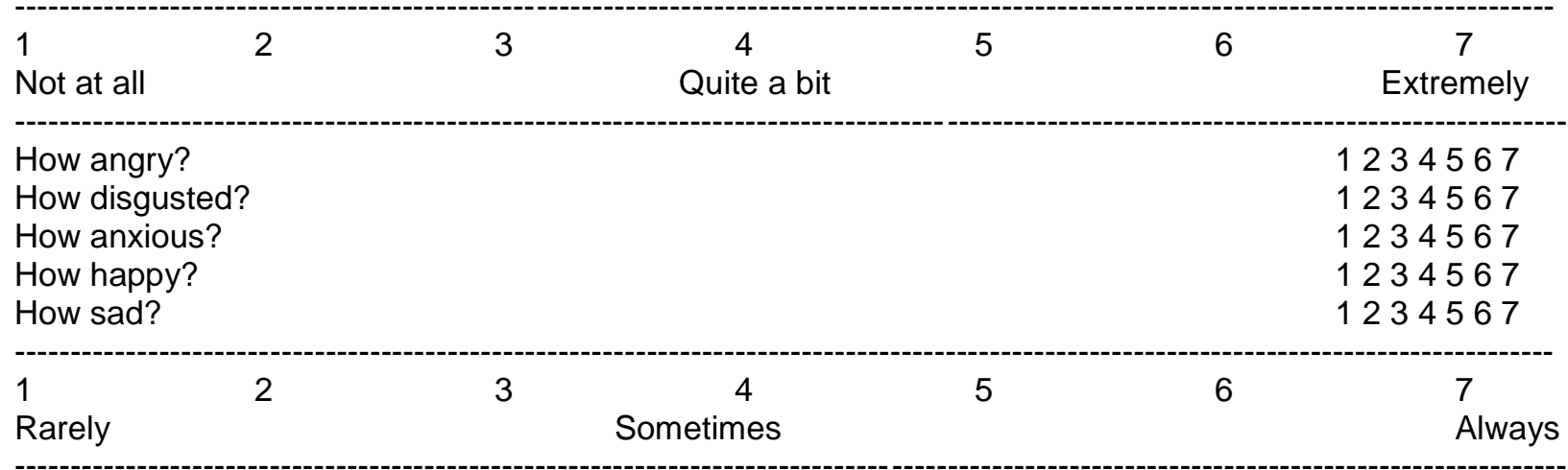

How often does your child need to be reminded to control his/her anger?

1234567

When you remind your child to control his/her anger, how

often are they able to control it?

1234567

When your child displays FEAR/ANXIETY how does it make you feel?

\begin{tabular}{|c|c|c|c|c|c|}
\hline $\begin{array}{l}1 \\
\text { Not at all }\end{array}$ & 3 & $\begin{array}{c}4 \\
\text { Quite a bit }\end{array}$ & 5 & 6 & $\begin{array}{c}7 \\
\text { Extremely }\end{array}$ \\
\hline $\begin{array}{l}\text { How angry? } \\
\text { How disgusted? } \\
\text { How anxious? } \\
\text { How happy? } \\
\text { How sad? }\end{array}$ & & & & & $\begin{array}{l}1234567 \\
1234567 \\
1234567 \\
1234567 \\
1234567\end{array}$ \\
\hline $\begin{array}{l}1 \\
\text { Rarely }\end{array}$ & 3 & $\begin{array}{c}4 \\
\text { netimes }\end{array}$ & 5 & 6 & $\begin{array}{l}7 \\
\text { Always }\end{array}$ \\
\hline
\end{tabular}

How often does your child need to be reminded to control his/her fear/anxiety?

1234567

When you remind your child to control his/her fear/anxiety, how

often are they able to control it?

1234567 
When your child displays SADNESS how does it make you feel?

\begin{tabular}{|c|c|c|c|c|c|}
\hline Not at all & 3 & $\begin{array}{c}4 \\
\text { Quite a bit }\end{array}$ & 5 & 6 & $\begin{array}{c}7 \\
\text { Extremely }\end{array}$ \\
\hline $\begin{array}{l}\text { How angry? } \\
\text { How disgusted? } \\
\text { How anxious? } \\
\text { How happy? } \\
\text { How sad? }\end{array}$ & & & & & $\begin{array}{l}1234567 \\
1234567 \\
1234567 \\
1234567 \\
1234567\end{array}$ \\
\hline $\begin{array}{l}1 \\
\text { Rarely }\end{array}$ & 3 & $\begin{array}{c}4 \\
\text { Sometimes }\end{array}$ & 5 & 6 & $\begin{array}{l}7 \\
\text { Always }\end{array}$ \\
\hline
\end{tabular}

How often does your child need to be reminded to control his/her sadness?

1234567

When you remind your child to control his/her sadness, how

often are they able to control it?

1234567

When your child displays HAPPINESS how does it make you feel?

\begin{tabular}{|c|c|c|c|c|c|}
\hline $\begin{array}{l}1 \\
\text { Not at all }\end{array}$ & 3 & $\begin{array}{c}4 \\
\text { Quite a bit }\end{array}$ & 5 & 6 & $\begin{array}{c}7 \\
\text { Extremely }\end{array}$ \\
\hline $\begin{array}{l}\text { How angry? } \\
\text { How disgusted? } \\
\text { How anxious? } \\
\text { How happy? } \\
\text { How sad? }\end{array}$ & & & & & $\begin{array}{l}1234567 \\
1234567 \\
1234567 \\
1234567 \\
1234567\end{array}$ \\
\hline $\begin{array}{l}1 \\
\text { Rarely }\end{array}$ & 3 & $\begin{array}{c}4 \\
\text { metimes }\end{array}$ & 5 & 6 & $\begin{array}{l}7 \\
\text { Always }\end{array}$ \\
\hline
\end{tabular}

How often does your child need to be reminded to control his/her happiness?

1234567

When you remind your child to control his/her happiness, how

often are they able to control it?

1234567

Thank you for your participation. If you'd like to add any other comments, please feel free to do so below. However, please refrain from using names, or any other identifiable information in your comments. 